\title{
MEMBRANE DISTILLATION: SOLAR AND WASTE HEAT DRIVEN DEMONSTRATION PLANTS FOR DESALINATION
}

\author{
R.Schwantes ${ }^{2 *}$, A. Cipollina ${ }^{1}$, F. Gross ${ }^{2}$, J. Koschikowski $^{2}$, D. Pfeifle ${ }^{2}$, \\ M.Rolletschek ${ }^{2}$, V. Subiela ${ }^{3}$ \\ ${ }^{1}$ Università degli Studi di Palermo,Dipartimento di Ingegneria Chimica, Gestionale, Informatica, Meccanica,, Viale \\ Delle Scienze (Edificio 6) 90128 Palermo (ITALIA) \\ ${ }^{2}$ Fraunhofer Institute for Solar Energy Systems (ISE), Heidenhofstr. 2, D 79110 Freiburg, Germany \\ ${ }^{3}$ Instituto Tecnológico de Canarias (ITC), Playa de Pozo Izquierdo, 35119 Santa Lucía, Las Palmas (Spain) \\ Corresponding author: rebecca.schwantes@ise.fraunhofer.de
}

\begin{abstract}
The development of small to medium size, autonomous and robust desalination units is needed to establish an independent water supply in remote areas. This is the motivation for research on alternative desalination processes. Membrane distillation (MD) seems to meet the specific requirements very well. This work is focused on experimental studies on full scale demonstration systems, utilizing a parallel multi MD-module setup. Three different plant concepts are introduced, one of them is waste heat driven and two of them are powered by solar thermal collectors. Design parameters and system design are presented. After the analysis of plant operation a comparison among the plants as well as a comparison with laboratory experiments is carried out and discussed. Impact of different feed flow rates, salinities, operating hours and process temperatures are taken into consideration and put into relation. GOR values and specific thermal heat demand are derived and compared. Energy balances of all three plants are given, uncovering heat losses and identifying room for improvement.
\end{abstract}

\section{Introduction}

The world's arid and semi-arid zones are already faced with massive water scarcity, which is prospected to increase in the upcoming decades. Therefore, the demand of desalination technologies is increasing rapidly. The development of medium size, autonomous and robust desalination units is needed to establish an independent water supply in remote areas. This is the motivation for research on alternative desalination processes. The robustness of the membrane process allows the following of alternating operation conditions given by e.g. solar energy. The Fraunhofer Institute for Solar Energy Systems (ISE) has been working on the development of energy self- sufficient desalination systems based on solar driven MD technology since 2001. The focus is put on module and system development. A performance analysis of a similar solar-driven desalination system with separated collector and heating loop was given by (Banat, 2006). Experience from previous project work on membrane distillation plants is discussed in), (Wieghaus, 2008) and (Koschikowski, 2009).

This work is focused on experimental studies on full scale demonstration systems, utilizing a parallel multi MD-module setup. The according MD technology back ground and module set up is presented in the paper "Desalination using membrane distillation: Experimental studies on full scale spiral wound modules" by D. Winter (Winter, 2011). From 2004-2008 different autonomous solar driven MD systems, covering a capacity range from 80 to 2000 liters/day, have been developed, installed and monitored. Simulation tools have been developed and validated with the data from pilot plant operation (Koschikowski, 2010) and theoretical Computational Fluid Dynamic analysis has been a performed for internal modules optimization (Cipollina et al, 2009). Two different system 
configurations for different capacities ranges were developed, the "Compact system" (Raluy \& al, 2011) and the "Two loop system".

This paper focuses on the two loop system design which is typically adopted for larger capacities. The main difference compared to the compact system is the use of a separated collector loop consisting of standard flat plate collectors and integrated heat storage for 24-hour /day operation. The collector loop and the desalination loop are hydraulically separated by a titanium heat exchanger.

Simulation tools were used to improve the MD- module technology and the overall system design. In the EU FP7 project MEDIRAS two two-loop systems were designed and installed in Pantelleria (Italy) and Gran Canary (Spain) between 2010 and 2011. Another two-loop system was installed in the frame of the BMBF funded project CuveWaters in the north of Namibia in 2010. Tab. 1 provides an overview on the technical specifications and boundary conditions of the two loop systems installed between 2010 and 2011. The three unique and different sites played an important part in the design of each of the desalination plants, as local geographical and infrastructural features had to be taken into consideration. In all three cases the systems were designed for operation without chemical pre-treatment of feed water since scaling and fouling resistance deemed to be one of the most beneficial properties of MD. This is part of the experimental investigations on the pilot plants. Hereafter, in this work the plants will be named by their location.

\section{Plant design}

Before construction of a desalination plant, the general hydraulic lay out was designed according to the particular purpose of the plant. Then simulation calculations in the program ColSim were carried out with the aim to dimension all relevant plant components with respect to the given design capacity and the particular geographical as well as meteorological site conditions. Namely, these components are the collector field and heat storage, as they define the amount and temporary distribution of heat available per day, as well as the number and size of MD modules to process the feed water into distillate. Auxiliary components as pumps, heat exchangers, valves and tubes were dimensioned according to the simulation results. Further, predictions concerning the operation time of the plant and output of distillate product water during the course of a year can be made.

In order to retrieve valid data from the simulation deck, a number of parameters such as weather records including solar radiation and ambient temperature of the region, technical parameters of solar thermal collectors, maximum volume flows of the different circuits and feed water properties as salinity and temperature were collected and provided as input for the simulations. Relevant results present a basis for the final plant design. 


\begin{tabular}{|c|c|c|c|c|c|c|c|}
\hline Location & $\begin{array}{l}\text { Date of } \\
\text { commis- } \\
\text { sionning }\end{array}$ & $\begin{array}{l}\text { Design } \\
\text { capacity } \\
\text { System }\end{array}$ & $\begin{array}{l}\text { Design } \\
\text { capacity } \\
\text { desalinati } \\
\text { on unit } \\
24 \mathrm{~h} \\
\text { operation }\end{array}$ & $\begin{array}{l}\text { Raw water } \\
\text { source }\end{array}$ & Heat supply & $\begin{array}{l}\text { Heat } \\
\text { storage }\end{array}$ & Cooling \\
\hline $\begin{array}{l}\text { Amarika } \\
\text { Namibia } \\
\text { Etosha } \\
\text { basin } \\
\text { (remote } \\
\text { inland } \\
\text { location) }\end{array}$ & $07 / 2010$ & $\begin{array}{l}4 \mathrm{~m}^{3} / \text { day at } \\
\text { alternating } \\
\text { temperatur } \\
\text { es } 65 \text { - } \\
80^{\circ} \mathrm{C}, 12 \\
\mathrm{MD} \\
\text { modules } \\
168 \mathrm{~m}^{2} \\
\text { membrane }\end{array}$ & $\begin{array}{l}5 \mathrm{~m}^{3} / \text { day at } \\
\text { evaporator } \\
\text { inlet } \\
\text { temperatu } \\
\text { re of } \\
80^{\circ} \mathrm{C} \text {, feed } \\
\text { flow rate } \\
\text { of } 4800 \\
1 / \mathrm{h} \text {, }\end{array}$ & $\begin{array}{l}\text { Ground } \\
\text { water, } \\
\text { drilling } \\
\text { well } \\
\sim 28000 \mathrm{ppm}\end{array}$ & $\begin{array}{l}\text { Solar } \\
\text { thermal flat } \\
\text { plate } \\
\text { collectors } \\
\text { single } \\
\text { glazed } \\
232 \mathrm{~m}^{2}\end{array}$ & $\begin{array}{l}12 \mathrm{~m}^{3}, \\
\text { integrated } \\
\text { heat storage }\end{array}$ & $\begin{array}{l}\text { Brine } \\
\text { cooling } \\
\text { tower. }\end{array}$ \\
\hline $\begin{array}{l}\text { Pantelleri } \\
\text { a, island } \\
\text { of Italy, } \\
\text { Power } \\
\text { station } \\
\text { equipped } \\
\text { with } \\
\text { Diesel } \\
\text { engines }\end{array}$ & $10 / 2010$ & $\begin{array}{l}5 \mathrm{~m}^{3} / \text { day } \\
\text { at constant } \\
\text { temperatur } \\
\text { e of } 80^{\circ} \mathrm{C} \text {, } \\
12 \mathrm{MD} \\
\text { modules, } \\
120 \mathrm{~m}^{2} \\
\text { membrane }\end{array}$ & $\begin{array}{l}5 \mathrm{~m}^{3} / \text { day } \\
\text { evaporator } \\
\text { inlet } \\
\text { temperatu } \\
\text { re of } \\
80^{\circ} \mathrm{C} \text {, feed } \\
\text { flow rate } \\
\text { of } 4800 \\
1 / \mathrm{h} \text {, }\end{array}$ & $\begin{array}{l}\text { Sea water } \\
\text { Mediterrane } \\
\text { an sea, open } \\
\text { intake } \\
35000 \mathrm{ppm}\end{array}$ & $\begin{array}{l}\text { Waste heat } \\
\text { from Diesel } \\
\text { engine }\end{array}$ & - & $\begin{array}{l}\text { Evaporative } \\
\text { brine } \\
\text { cooler, heat } \\
\text { exchanger }\end{array}$ \\
\hline $\begin{array}{l}\text { Gran } \\
\text { Canaria } \\
\text { Spain } \\
\text { Test Site } \\
\text { of ITC }\end{array}$ & $03 / 2011$ & $\begin{array}{l}3.5 \mathrm{~m}^{3} / \text { day } \\
\text { at } \\
\text { alternating } \\
\text { temperatur } \\
\text { es } 65 \text { - } \\
80^{\circ} \mathrm{C} \text {, } \\
12 \mathrm{MD} \\
\text { modules, } \\
120 \mathrm{~m}^{2} \\
\text { membrane }^{2}\end{array}$ & $\begin{array}{l}5 \mathrm{~m}^{3} / \text { day at } \\
\text { evaporator } \\
\text { inlet } \\
\text { temperatu } \\
\text { re of } \\
80^{\circ} \mathrm{C} \text {, feed } \\
\text { flow rate } \\
\text { of } 4800 \\
1 / \mathrm{h} \text {, }\end{array}$ & $\begin{array}{l}\text { Sea water } \\
\text { Atlantic } \\
\text { ocean, } \\
\text { beach well } \\
\text { intake } \\
35000 \mathrm{ppm}\end{array}$ & $\begin{array}{l}\begin{array}{l}\text { Solar } \\
\text { thermal flat } \\
\text { plate }\end{array} \\
\text { collectors } \\
185,6 \mathrm{~m}^{2} \\
\left(92.8 \mathrm{~m}^{2}\right. \\
\text { single } \\
\text { glassed, } \\
92.8 \mathrm{~m}^{2} \\
\text { double } \\
\text { glazed) }\end{array}$ & $\begin{array}{l}7,2 \mathrm{~m}^{3} \\
\text { stand alone } \\
\text { heat storage }\end{array}$ & $\begin{array}{l}\text { Brine } \\
\text { cooling } \\
\text { tower, heat } \\
\text { exchanger }\end{array}$ \\
\hline
\end{tabular}

Tab. 1: Specifications and design parameters of two loop systems installed in 2010 and 2011

Tab. 1 above gives a selection of the most significant design parameters for the different plants. Heat storage sizing by simulation results from the collector field size and weather data of the installation area, enabling the estimation of a daily heat intake by the system. With the design temperature of maximum $80{ }^{\circ} \mathrm{C}$ for the distillation process, the need to dispense this heat evenly throughout 24 hours presents a certain storage size.

The 24 hour heat supply provided by the generators on Pantelleria (Fig. 1) makes a heat storage for evening and night time operation obsolete.

The chosen number of MD modules is mainly dependent on the maximum daily capacity aimed for, as in this case $5 \mathrm{~m}^{3}$. In Namibia, a batch of MD modules with longer channels (10 m opposed to $7 \mathrm{~m}$ ) and therefore larger membrane surface of approximately $14 \mathrm{~m}^{2} /$ module in contrast to $10 \mathrm{~m}^{2} /$ module was put into test, to improve the heat recovery respectively to reduce the specific thermal energy demand.

\subsection{Pantelleria System}


Generator 5MW all Mediterranean Island between Sicily and Tunisia, presents unlimited access to sea water. energy for the membrane distillation process is gained from the cooling circuit of a diesel power station. Its generators produce waste heat within a usable temperature range for membrane distillation $\left(70-80^{\circ} \mathrm{C}\right) 24$ hours per day. The produced water from the MD plant is used for industrial purposes. In particular, low conductivity water is adopted as make-up water in cooling circuits of the diesel engines and also for the preparation of urea to be used in the DeNOx unit installed in order to reduce the NOx emission in the larger diesel generator of the power station. In both cases a distillate conductivity $<100 \mu \mathrm{S}$ is required.

Due to these boundary conditions, the Pantelleria system was mainly designed for steady state operation. It is designed for a maximum distillate capacity of $5 \mathrm{~m}^{3} /$ day in $24 \mathrm{~h}$ operation mode. The raw water source of the MD system is the sea water intake of the power plant through which seawater is needed for cooling. For experimental investigations an internal recirculation of the brine is possible. For cooling, a brine evaporative cooler concentrator (BECC) was developed by the University of Palermo and University of Bremen (Cipollina, 2011).

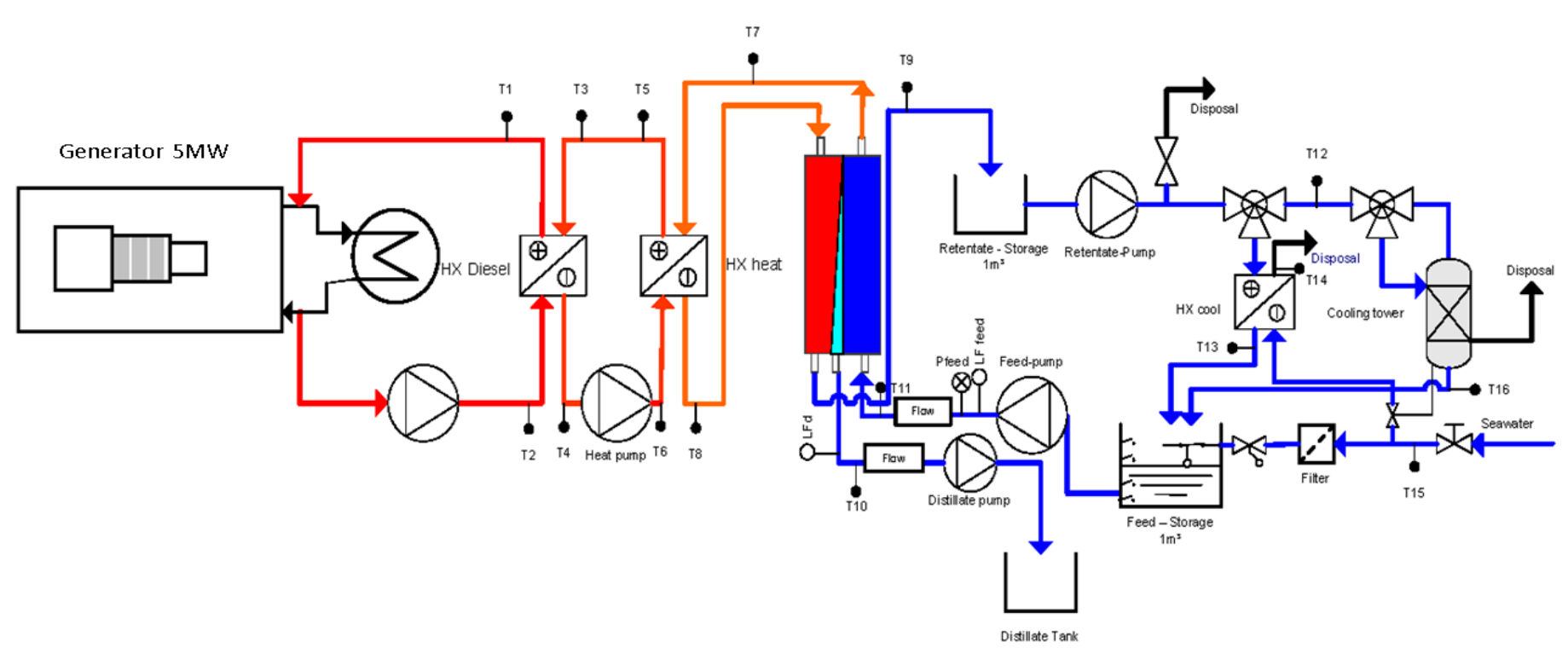

Fig. 1: Schema of the Pantelleria plant

Fig. 1 shows a flow chart of the system design with sensors in Pantelleria. Heat exchanger HX Diesel is installed inside the cooling circuit of the diesel engine. It transfers the heat into the intermediate heat circuit of the desalination unit. From there on, heat is transferred through $H X$ heat into the evaporator side of the MD process. On the condenser side, the feed pump conveys the feed water from a feed storage tank to the MD-modules. The water in the Feed-Storage can be either raw seawater, or a mix of recirculated brine from the evaporator outlet of the MD system and raw seawater. Recirculated brine can be cooled by two different devices. $H X$ cool is flooded with seawater on the secondary side to lower the brine temperature. The cooling tower on the right side of the diagram represents the evaporative brine cooler. This can be used instead of, or together with the $H X$ cool and has the double aim of cooling the recirculating brine and evaporating/concentrating the brine blow-down in order to reduce the relevant disposal volume (Cipollina, 2011). After exiting the modules, the distillate is directed to a distillate tank. Both feed volume flow and distillate volume flow are measured by magnetic flow meters and logged in the data acquisition system together with 
temperature, pressure and conductivity values. Disposal arrows indicate the different possibilities to discharge brine and cooling water.

The images in Fig. 2 show the CAD drawing and the ready installed MD system in Pantelleria. It consists of $12 \mathrm{MD}$ modules with $10 \mathrm{~m}^{2}$ membrane surface each, connected parallel in three rows of four, situated on an aluminum profile rack. Feed and retentate storage tanks of $1 \mathrm{~m}^{3}$ each are located above the pumps, valves and flow meters.
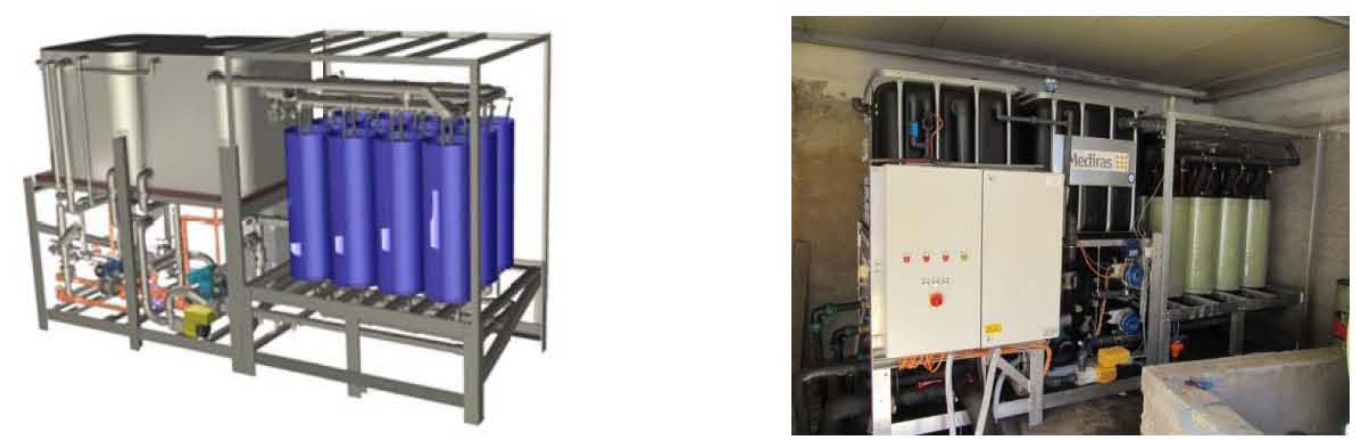

Fig. 2: 3D design and ready installed pilot MD system in Pantelleria

The image to the right shows the completed system with switch box, installed under a concrete shed on the power station premises. Underground tubing to the power station connects the $H X$ heat with the HX Diesel. Distillate is directed out of the system to an external storage tank.

\subsection{Namibia System}

In Amarika, Namibia, the raw water is taken from a brackish water well. Thermal and electrical energy are supplied by PV and solar thermal collectors entirely. The site, in midst of the African bush, has no infrastructure.

Water taken from the membrane distillation plant, is used by the village community as drinking water.

The solar driven desalination system was designed for the fresh water production of up to $4 \mathrm{~m}^{3}$ in 24 hour operation from brackish raw water of $15-28 \mathrm{~g} / \mathrm{kg}$ salinity. The hydraulic layout is shown in Fig. 3. Heat supply is brought into the system through the $232 \mathrm{~m}^{2}$ collector array, type Ecosol 2.32 manufactured by the company European Solar Engineering (ESE), and transferred to the intermediate heat circuit by $H X$ coll. Inside this circuit two valves control the charge and discharge of the heat storage according to the heat required at $H X$ heat. During day time operation the inlet temperature of $H X$ heat respectively the evaporator inlet temperature of the MD modules is controlled by valve temp by mixing hot water from the $H X$ col (branch B) with cold water from the storage bottom (branch A) to the adequate set temperature. At the same time excess heat is stored in the heat storage because the same amount of hot fluid is introduced on the storage top as cold fluid is tabbed from the storage bottom.

In evening and night time operational mode, the entire excess heat collected during sun hours is extracted from the storage to sustain operation for as long as an efficient operation temperature of at least $60^{\circ} \mathrm{C}$ is available. Once passed $H X$ heat, the energy is used to power the desalination unit.

On the condenser side a feed storage gives the possibility to mix the raw water with recirculated brine, which is an important feature in this case due to limited raw water resources. A standard industrial open circuit cooling tower is installed in the evaporator outlet line to keep a low condenser 
inlet temperature. The three way valve beforehand controls a partial discharge of brine out of the system, to be replaced by raw water. Distillate produced by the desalination unit is collected in a $2 \mathrm{~m}^{3}$ tank and then pumped to a central elevated storage tank for drinking use.

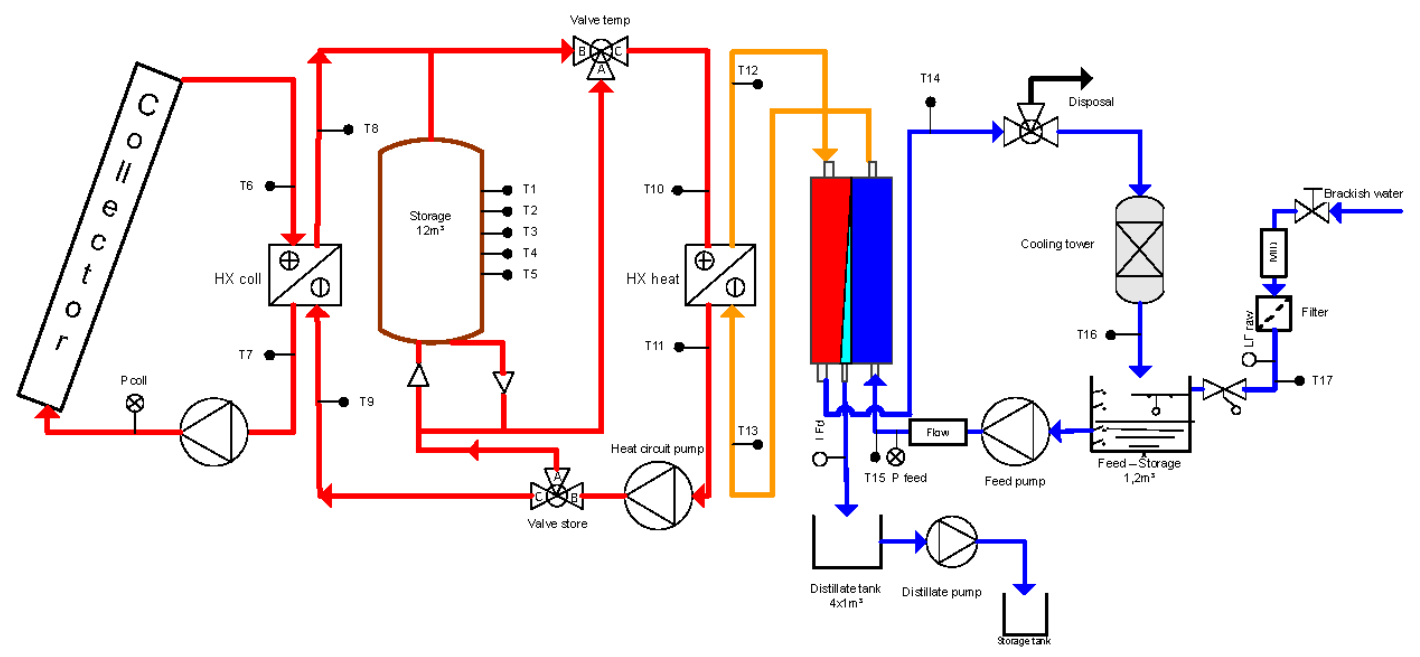

Fig. 3: Schema of the Namibia plant

In order to make transportation and installation more convenient the complete system including desalination unit, controls and heat storage $\left(12 \mathrm{~m}^{3}\right)$ were installed inside a $20 \mathrm{feet}$ standard container. The set up can be seen in Fig. 4. In the construction drawing to the left, the division of the container is clearly visible. Behind the module rack with pumps and valves underneath, the heat storage takes up $2 / 3$ of the container volume. The image on the right side shows the ready constructed plant with the MD modules in front and switch cabinet on the right hand side.
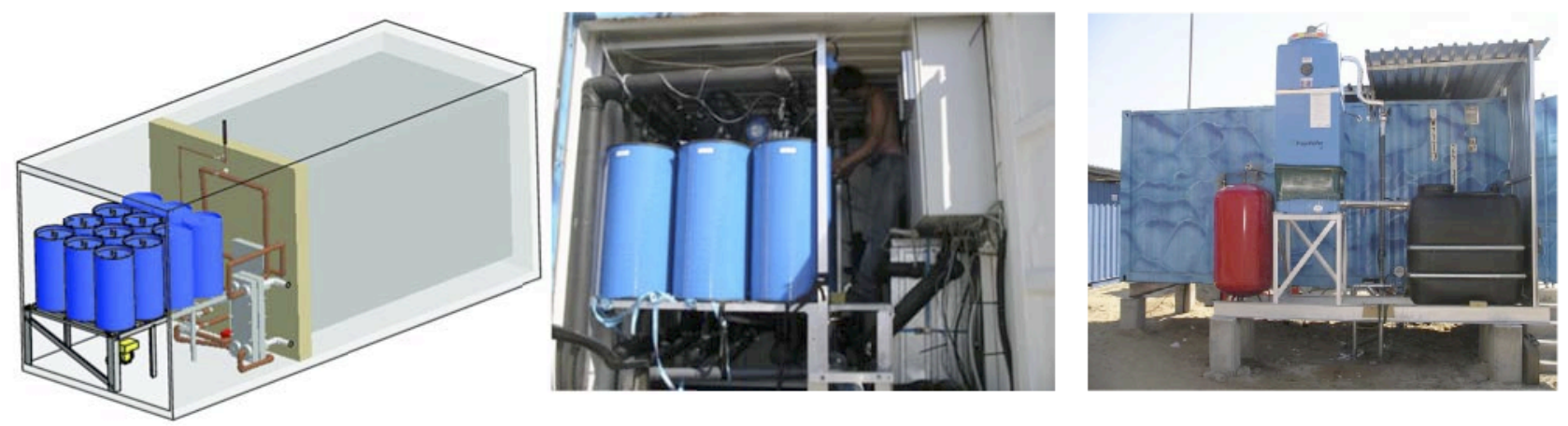

Fig. 4: CAD drawing of the Namibia system, view into the ready installed container and components

The collector field consists of 100 flat plate collectors with a total aperture area of $232 \mathrm{~m}^{2}$. All collectors are connected in parallel in order to minimize the pressure drop. A high pressure drop requires more pumping and hence more electrical energy. Electrical energy is supplied by a PV system including batteries and DC-AC converter. The Membrane distillation unit consists of 12 MDmodules each of $14 \mathrm{~m}^{2}$ membrane area. These slightly larger modules are an experimental attempt to lower the specific thermal energy demand. All MD modules are connected in parallel to reduce the pressure drop of the desalination system. Besides causing a higher electrical energy consumption, the a pressure drop over 0,9 bars can damage the internal material structure of the MD modules and must be prevented. 
Computational controls enable a fully automatic operation. However, the control and data acquisition system are connected to a satellite communication system for remote control possibilities and daily data transfer.

\subsection{Gran Canary System}

The Gran Canary plant is situated on the grounds of the Instituto Tecnologico de Canarias, a partner within the MEDIRAS project. Seawater at a salinity of $35 \mathrm{~g} / \mathrm{kg}$ is constantly supplied by a beach well and provided by a central pumping system. Thermal energy comes from a solar thermal collector field. Electrical energy is taken from the institute's grid. The distillate is pumped into a central cistern and used for irrigation. Good infrastructure and the location on institute premises provide best conditions for long term research and monitored field experience. The annual gain of solar radiation on the horizontal surface is about $2000 \mathrm{kWh} /\left(\mathrm{m}^{2} \mathrm{y}\right)$.

As with Namibia this plant is also designed and constructed inside a 20 feet standard container. However, the interior follows a different concept without an integrated heat storage and therefore with additional working space.

The collector field of the plant consists of two arrays of $93 \mathrm{~m}^{2}$ each amounting to a total of $186 \mathrm{~m}^{2}$. One consists of single glazed collectors of the same type and brand (Ecosol 2.32, ESE) as in the Namibia plant. This array was installed by the MEDIRAS project partner ESE within the scope of the project. ESE planned to use the array for experimental investigation of a new bi-phasic operation mode and added some modified components to the hydraulic setup. Due to these modifications, the array can only be operated at normal-pressure. The other array consists of double glazed collectors with reduced convective heat losses which are reused from a previous project on the same site. As can be seen in Fig. 5, both arrays are connected to the heat circuit by heat exchangers $H X$ coll 1 and $H X$ coll2. Similar to the Namibia plant, two three way valves control the charge and discharge of the heat storage. However, the storage tank has two different inlets and outlets which either lead to a stratifyer or a pipe inlet. This arrangement was chosen for experimental reasons in order to investigate the possible advantages of a stratifyer.

In total the plant is fitted with three flow meters in heat circuit, feed circuit and distillate outlet, logged by the data acquisition system. Collector circuit $\mathrm{A}$ is equipped with a manual flow meter of low accuracy. Once the temperature on the secondary side of $H X$ heat has reached $80^{\circ} \mathrm{C}$, the desalination unit begins operation and the heat is transferred to the evaporator channel of the MDmodules. As in Pantelleria, the Gran Canary plant has $12 \mathrm{MD}$ modules of $10 \mathrm{~m}^{2}$ membrane surface each, however, opposed to Pantelleria, set in two rows of six as can be seen in Fig. 6. This different configuration was chosen in order to investigate a different flow regime within the manifolds for the distribution of hot and cold feed streams and ensure easier access and maintenance possibilities inside the container. 


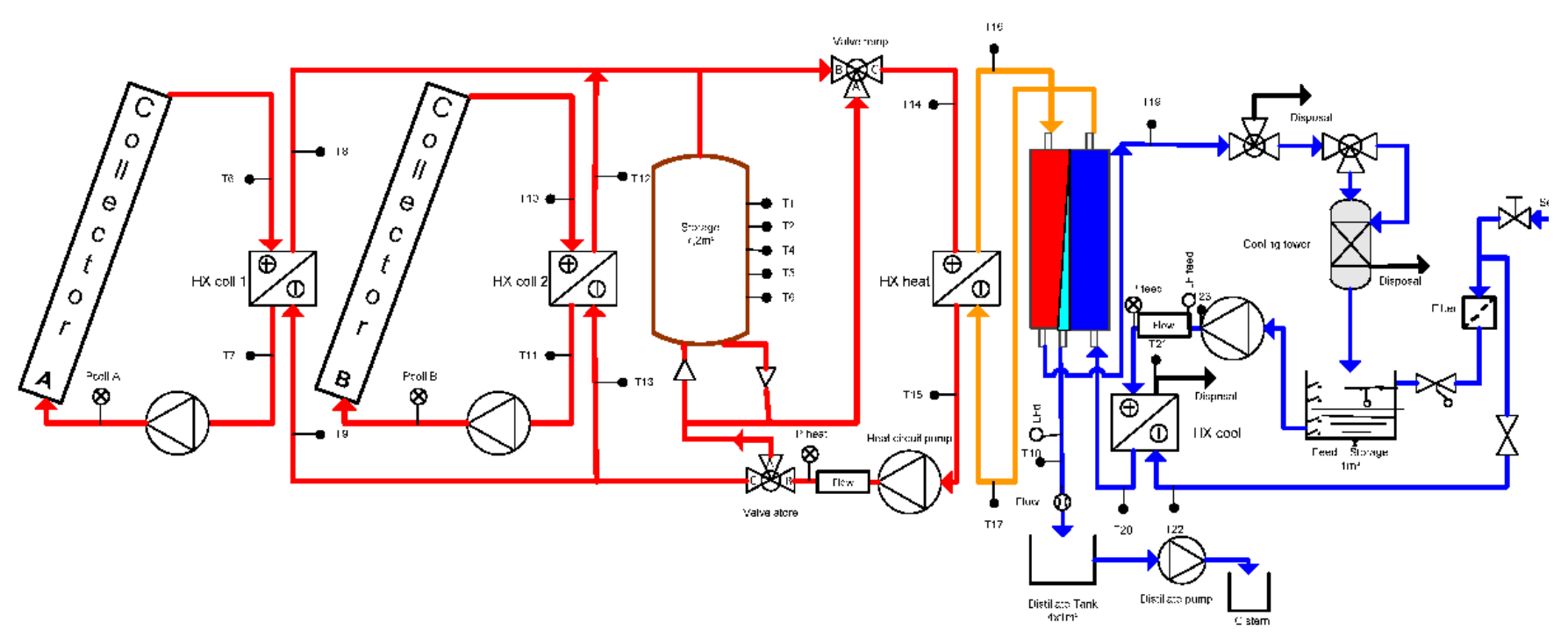

Fig. 5: Schema of the Gran Canary plant

The cooling strategy can be compared to Pantelleria. An experimental brine cooler, developed by the University of Bremen, set on the roof of the container is complemented by a heat exchanger fed with cold seawater on its secondary side.

Fully automatic operation is provided and remote access to the controls and data acquisition is additionally possible.
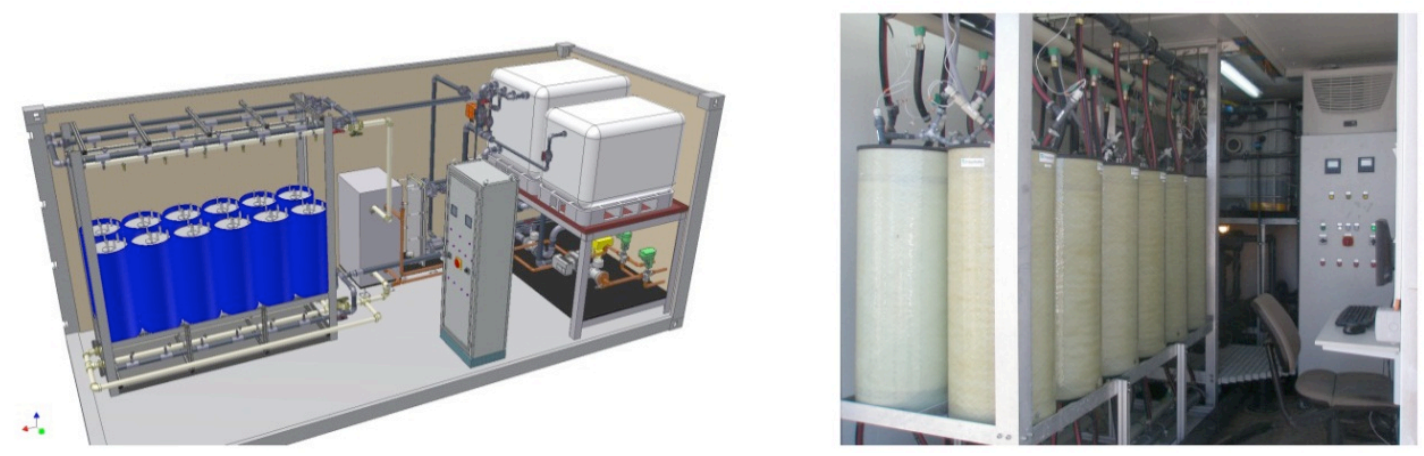

Fig. 6: 3D design of the system and installed plant on Gran Canary

The construction drawing on the left side of Fig. 6 shows a lot more working space and better module accessibility inside the 20 feet container than with the Namibia plant. This is one of the beneficial effects of the alternative flow regime. Two tanks are located in the back of the container above the pumps and valves rack. Work space around the switch box and the modules is generous, leaving enough room for a computer workstation, as can be seen on the right side of the photograph in Fig. 6. Furthermore, all MD module connections to the PP and PVC manifolds above are well visible together with module temperature sensors.

\subsection{Plant control system}

For a better understanding of plant operation and energy analysis in the following sections, an overview of the main control temperatures is given in table 2 .

$\begin{array}{ccccc}\begin{array}{c}\text { Collector circuit } \\ \text { on/off }\end{array} & \begin{array}{c}\text { Heat circuit } \\ \text { on/off }\end{array} & \begin{array}{c}\text { Feed circuit } \\ \text { on/off }\end{array} & \begin{array}{c}\text { Valve Temp } \\ \text { open/close }\end{array} & \begin{array}{c}\text { Valve Store } \\ \text { close }\end{array}\end{array}$




\begin{tabular}{lccccc} 
& {$\left[{ }^{\circ} \mathrm{C}\right]$} & {$\left[{ }^{\circ} \mathrm{C}\right]$} & {$\left[{ }^{\circ} \mathrm{C}\right]$} & {$\left[{ }^{\circ} \mathrm{C}\right]$} & {$\left[{ }^{\circ} \mathrm{C}\right]$} \\
\hline Namibia & $49 / 46$ & $49 / 46$ & $60 / 57$ & 72 & 60 \\
\hline Gran Canary & $65 / 58$ & $68 / 62$ & $67 / 60$ & $83 / 80$ & 62 \\
\hline Tab. 2: Programmed initiation and stop temperatures in the plants control systems
\end{tabular}

The collector circuit pumps are programmed to begin operation at $49{ }^{\circ} \mathrm{C}$ in Namibia and $65{ }^{\circ} \mathrm{C}$ in Gran Canary. These temperatures were chosen depending on the potential evaporator inlet temperature for each plant. A hysteresis prevents the pumps from undergoing a frequent start and stop phase during the heating of each circuit. The off temperatures in tab. 2 represent the lower boundaries of the hysteresis. Even though the Collector circuit and Heat circuit initiation temperatures are identical in Namibia, the pumps begin operation with a time difference as the heat must first be transported from one circuit to the adjacent circuit. The temperature sensors triggering the control system are located at the heat exchangers of the respective circuit. Valve Temp indicates the opening or closing temperatures of the valve guiding heat into the storage tank. These are equal to the respective evaporator inlet temperatures. When surpassed, the heat is stored for later use. Valve Store close is the base temperature of the storage tank at which storage operation of the feed circuit is discontinued for efficiency reasons.

As Pantelleria is driven by a constant heat source and has no heat storage or collector circuit the control sequence is less complex with a switch-on temperature of the feed pump at $60^{\circ} \mathrm{C}$.

All three plants have programmed safety controls regarding maximum pressure $(0,9$ bars $)$ and maximum temperature $\left(90^{\circ} \mathrm{C}\right)$ in the feed circuit for protection of the modules. When operated manually, these safety controls remain active. They are made redundant by independent thermal switches and pressure sensors for the unlikely event of a computational failure. In manual operation mode, volume flows and control temperatures can be varied freely for experimental operation modes.

\section{Plant operation analysis}

In the following, an analysis of the three plants standard operation will be made which is focused on daily performance.

\subsubsection{Pantelleria}

The waste heat powered Pantelleria plant remains independent from solar irradiation and therefore presents the steadiest operation throughout 24 hours. The evaporator inlet temperature is typically between 65 and $75^{\circ} \mathrm{C}$ depending on the mechanical load of the diesel engine. This is slightly lower than the predicted design temperature of $80^{\circ} \mathrm{C}$ and results in an efficiency reduction of the desalination unit which will be discussed later.

Fig. 7 presents a typical 24 hour operation with the most significant parameters. The sampling interval of the data acquisition in the Pantelleria system is 5 seconds. 


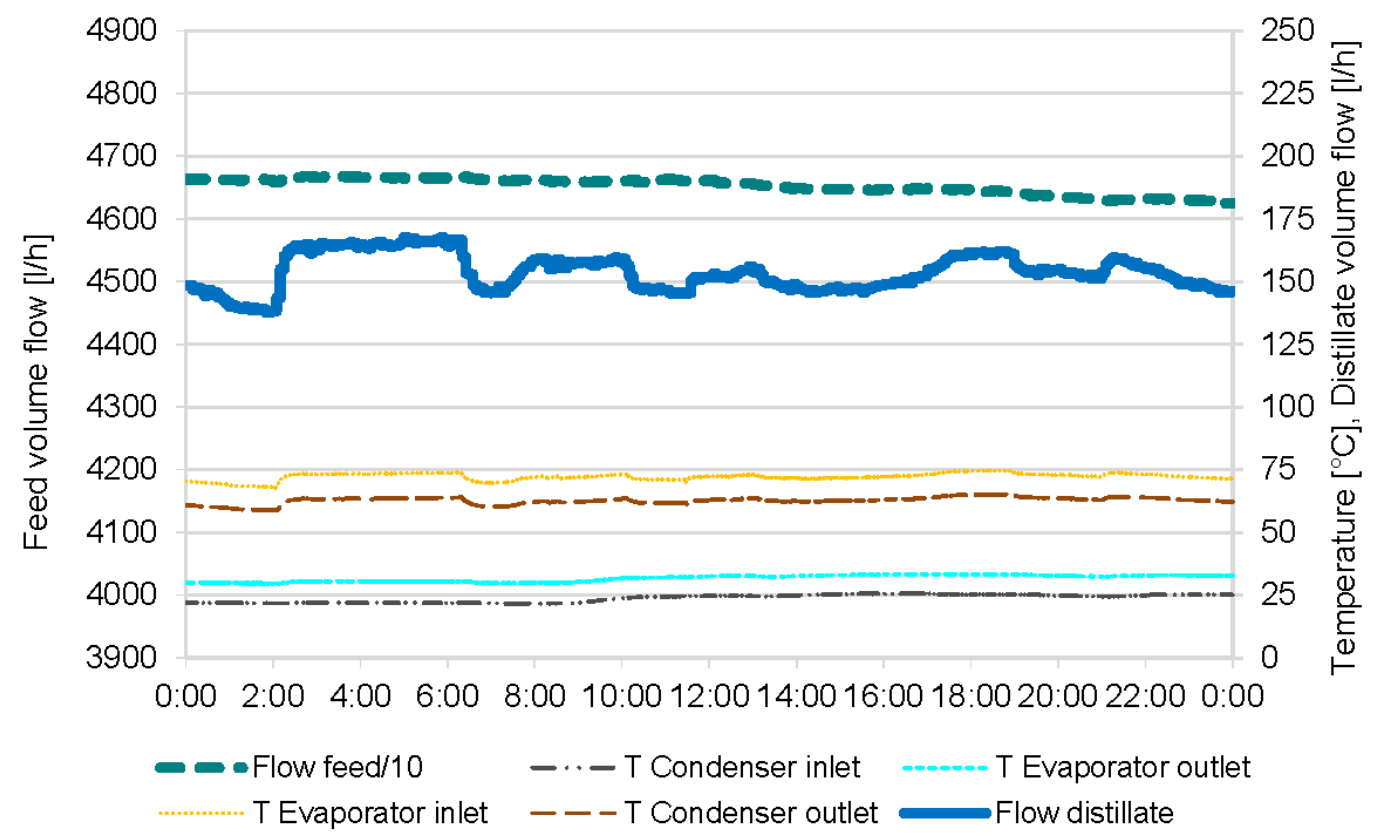

Fig. 7: Data for a day in November 2010, Pantelleria

Condenser inlet and evaporator outlet temperatures (T9 and T11, Fig. 1) remain relatively constant throughout the day, whereas more variance can be perceived in the condenser outlet (avg. $62.8^{\circ} \mathrm{C}$ ) and evaporator inlet (avg. $72.2^{\circ} \mathrm{C}$ ) temperatures (T7 and T8, Fig. 2), which is a result of the varying heat input from the Diesel generator. $\Delta T_{h}$, here $9.4 \mathrm{~K}$ on average, is the difference of evaporator inlet and condenser outlet, whereas the index $\mathrm{h}$ stands for the hot side of the module. This temperature difference is used for specific heat consumption and GOR value calculations later in this work. Distillate output shows a correlating modulation to the varying driving force temperatures on the hot side of the MD modules. The feed volume flow is set to a fixed value, only fluctuating slightly during the measuring period. Feed salinity was between $47-49 \mathrm{~g} / \mathrm{kg}$, which is higher than the raw seawater intake, due to the recirculation of the brine through the evaporative brine cooler and the $H X$ cool, back into the feed storage tank. The percentage of recirculation can be controlled by a valve and part of the brine disposed of. On the day of the data presented in Fig. 7, the plant produced 3688 liters of distillate in 24 hours at an average conductivity of $29 \mu \mathrm{S} / \mathrm{cm}$.

Due to the favorable near steady-state operation of the plant, experimental investigations on the desalination unit where carried out. 


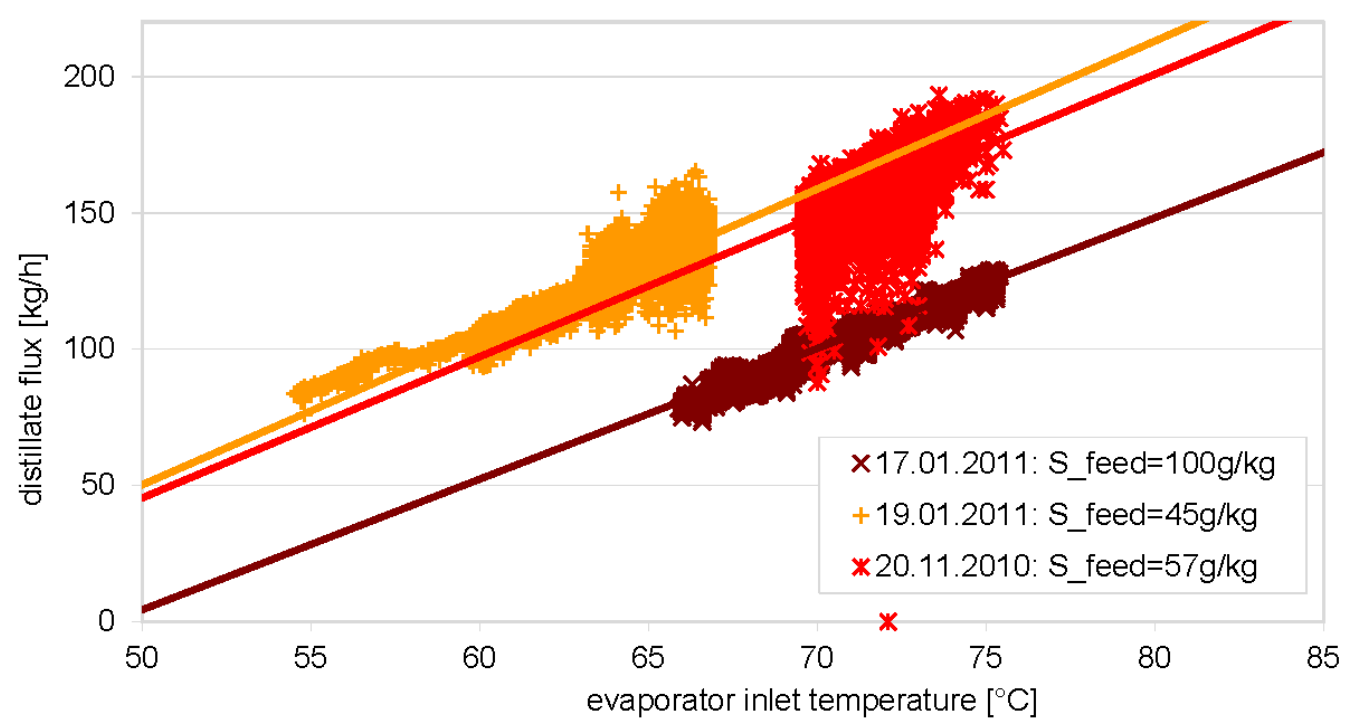

Fig. 8: Experimental investigations of the Pantelleria plant demonstrating the effect of feed water salinity and evaporator inlet temperature on the distillate flow rate

The graphs in Fig. 8 show results from plant operation at different evaporator inlet temperatures between 55 and $75^{\circ} \mathrm{C}$ and different feed salinities of 45,57 and $100 \mathrm{~g} / \mathrm{kg}$. The mean condenser inlet temperature was $25^{\circ} \mathrm{C}$. As can be seen from the trend line of average values the distillate volume flow increases with an increase of the evaporator inlet temperature and decreases significantly with an increase of feed salinity. An increase of feed salinity from 45 to $100 \mathrm{~g} / \mathrm{kg}$ at an evaporator inlet temperature of $75^{\circ} \mathrm{C}$ induces a reduction of the distillate flow rate from about 180 to $125 \mathrm{~kg} / \mathrm{h}$.

The impact of evaporator inlet temperature and salinity on the MD process has been investigated and presented under laboratory conditions with (Winter, 2011). These measurements verify the previous assumptions in a field test. A lower evaporator inlet temperature decreases the driving force temperature difference of the process, while higher salinities generate a reduction in the feed vapour pressure, thus also reducing the effective driving force of the process generate a reduction in the feed vapour pressure, thus also reducing the effective driving force of the process. As can be seen from the graphs in Fig. 8, the Pantelleria plant is capable of producing about $200-220 \mathrm{l} / \mathrm{h}$ distillate if the plant could be operated according to the primary design parameters ( $\mathrm{T}$ evaporator in $=80^{\circ} \mathrm{C}, \mathrm{S}$ feed $=50 \mathrm{~g} / \mathrm{kg}$ ) which is equal to $4.8-5.3 \mathrm{~m}^{3} /$ day and complies with the design figures.

\subsection{Namibia}

Dependency on fluctuating solar irradiation for the supply of heat and electricity requires transitory operation modes of the MD system. The necessity of a heat storage to preserve and distribute excess heat collected during the day, becomes obvious. Fig. 9 presents the trends of solar radiation and operating parameters of a sunny day in May 2011. The sampling interval of the data acquisition in the Namibia system is 10 seconds.

At an irradiation level of approximately $550-580 \mathrm{~W} / \mathrm{m}^{2}$ the feed pump begins operation at about 8:55 o clock. Condenser outlet and evaporator inlet temperatures (T13 and T12, Fig. 3) rise significantly as the heat is transferred through the collectors and heat circuit to the desalination unit. The evaporator outlet (T14) temperature rises slightly and is cooled back down to condenser inlet (T15) temperature by the cooling tower and the mixture with raw water. The feed pump is set to a value of around $4300 \mathrm{l} / \mathrm{h}$. In the programming of the system a sequence switches the setting of the pump to 
different levels depending on the available heat provided by the collectors respectively and the heat circuit.

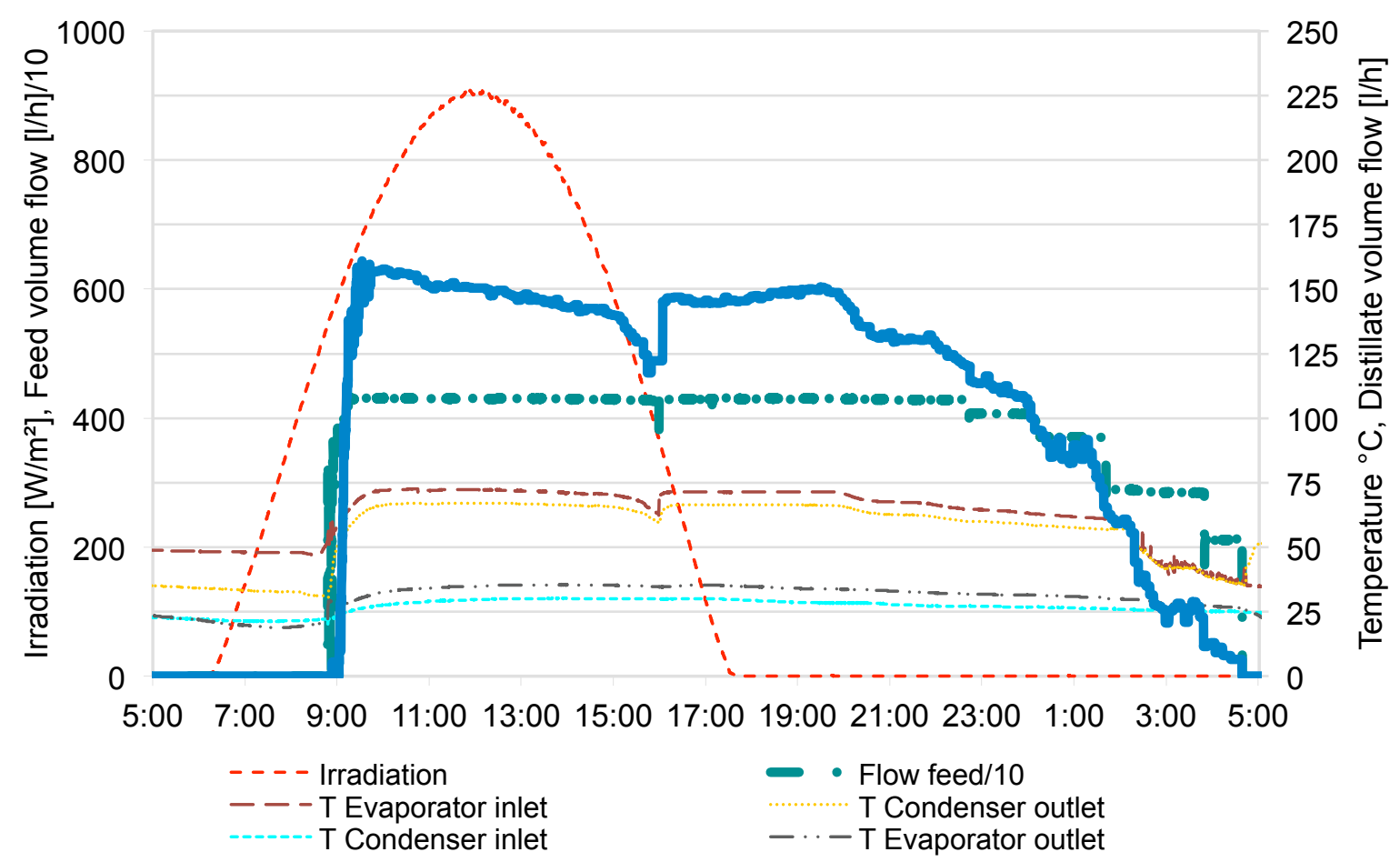

Fig. 9: Data for a sunny day of May 2011, Namibia

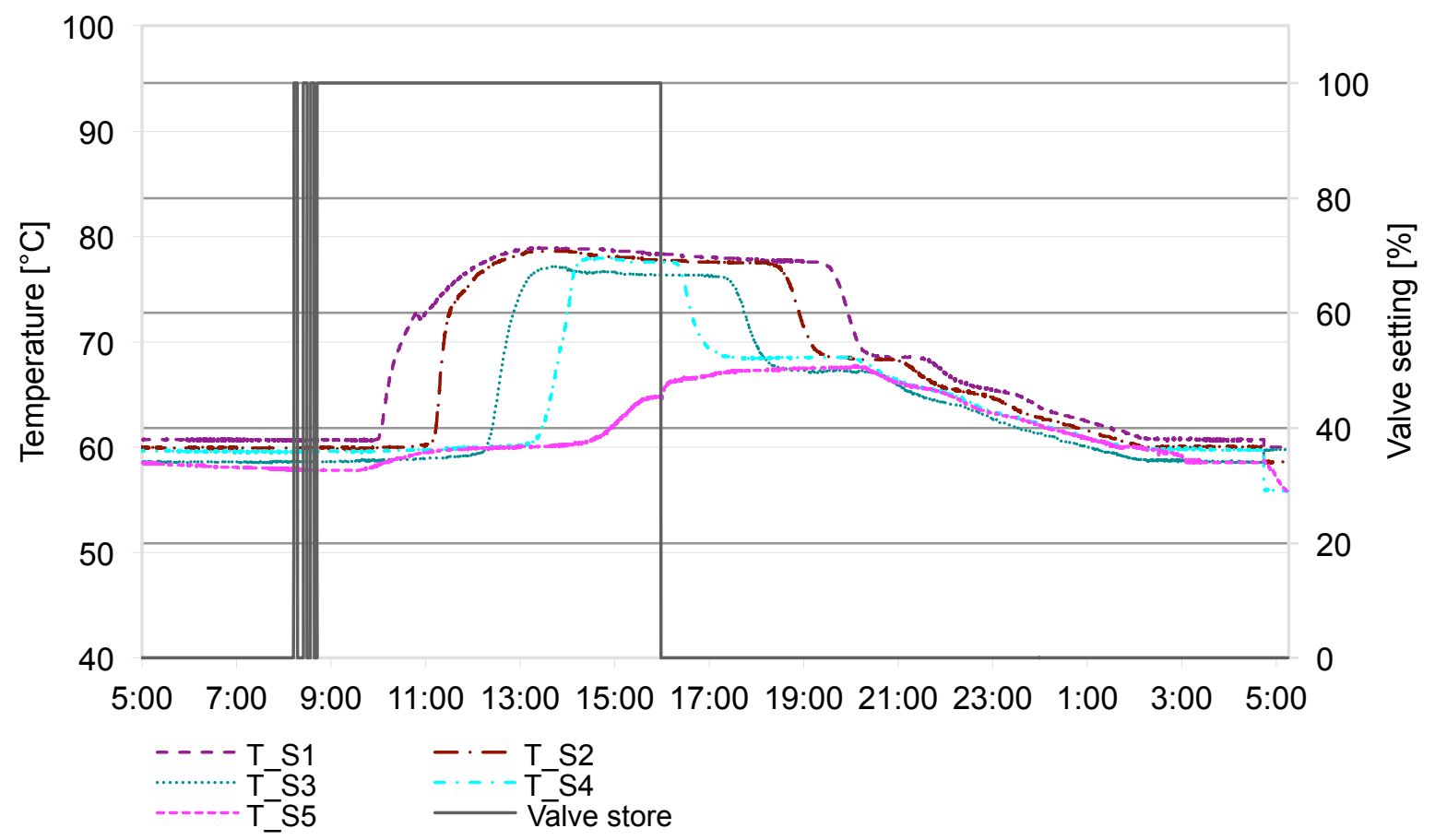

Fig. 10: Charge and discharge of heat storage, Namibia

Distillate production initiates shortly after the reaching of working temperatures at about 9:05 o clock. A slight drop of distillate output can be well perceived during daytime operation which coincides precisely with the slight drop in evaporator inlet temperature. This is the point at which the 


\section{Article post-print. \\ Please cite e as: R. Schwantes, et al., Membrane distillation: Solar and waste heat driven demonstration plants for desalination, Desalination. (2013), http://dx.doi.org/10.1016/j.desal.2013.04.011}

plant switches from collector heat supply to storage heat supply. As in Pantelleria, the plant is operated approx. $10 \mathrm{~K}$ below the design temperature. The evaporator inlet temperature is between $65-$ $73{ }^{\circ} \mathrm{C}\left(69.7{ }^{\circ} \mathrm{C}\right.$ on average $)$ and dampens the efficiency of the desalination unit. The condenser outlet temperature averages at $64.8^{\circ} \mathrm{C}$ resulting in a $\Delta T_{h}$ of approximately $4.9 \mathrm{~K}$ between evaporator inlet and condenser outlet. This is the smallest value of all three plants, due to the longer channel modules and the higher condenser inlet temperature of $30^{\circ} \mathrm{C}$.

With the falling irradiation level, at approximately 16:00 o 'clock the heat from the collector loop falls below the sufficient level to sustain an efficient evaporator inlet temperature. This can be seen at the dip in evaporator inlet and condenser outlet temperatures at this point and the significant drop in distillate productivity. Then, the plant switches to storage operation, using the excess heat from the day time to power the desalination unit for the rest of the night and in the case of Fig. 9, into the next day. With the further depletion of heat, the available temperature level in the storage slowly drops, influencing the distillate productivity coincidently.

Fig. 10 gives a 24 hour view of the temperatures in the heat storage and the activity of valve store (Fig. 3) controlling the discharge of the heat storage. At around 8:35 o'clock it changes its setting to $100 \%$ (setting B-C) in order to supply the MD system with heat from the collector loop only. The temperature inside the tank is layered with the top part of the tank heating up first due to the position of the inlet nozzle on top. This can be seen in Fig. 10 as the temperature sensors T1- T5 are distributed evenly along the height of the tank. As soon as excess heat is produced by the collectors during the day time, valve store guides it into the storage causing the displayed gradual layering. At the point of changing operational mode at about 16:00 o 'clock to storage operation, valve store switches to $0 \%$, then taking all heat for the desalination unit from the storage tank. Valve temp, also visible in the flow chart of Fig. 3, is not displayed in Fig. 10, as it is a manual temperature valve set to mix and supply $75^{\circ} \mathrm{C}$ on the primary side of $H X$ heat.

At this moment, the storage is not completely loaded, leaving $\mathrm{T} 5$ at around $65{ }^{\circ} \mathrm{C}$. The layering inside the storage is gradually dissolved and as of 21:00 o'clock, mixed together to a nearly even mix temperature which decreases until the end of storage operation. The first big drop in storage temperature between 19:00 - 21:00 o clock can be perceived in Fig. 9 as a significant drop in distillate output and a slight drop in evaporator inlet temperature.

The plant sustains operation until the heat level in the tank is back at or slightly under $60^{\circ} \mathrm{C}$ on all levels which resembles the initial starting temperature. On the day used in Fig. 9-10, 2079 liters of distillate where produced at an average of $850 \mu \mathrm{S} / \mathrm{cm}$ from $1280 \mathrm{kWh}$ of solar irradiation. Due to micro leakages in some of the MD modules the distillate conductivity is higher than in the Gran Canary and Pantelleria plant. However, the leakages are so minor that the drinking quality of the product water is not jeopardized.

\subsection{Gran Canary}

Displaying the same parameters as Fig. 9, Fig. 11 the operating conditions of a sunny day in October 2011 on Gran Canary. The sampling interval of the data acquisition in the Gran Canary system is 15 seconds.

Plant operation is initiated at around 11:06 o clock with $400 \mathrm{~W} / \mathrm{m}^{2}$ irradiation and distillate production picks up approximately $39 \mathrm{~min}$ later. The feed pump is set to a fixed value of $3600 \mathrm{l} / \mathrm{h}$ with small variances due to the control sequence of the feed pump frequency converter. In contrast to the other two plants, the Gran Canary system runs at the design temperature close to $80^{\circ} \mathrm{C}$. Condenser outlet temperature (T17, Fig. 5) remains around $72{ }^{\circ} \mathrm{C}$ during daytime operation, giving a $\Delta T_{h}$ of $8 \mathrm{~K}$ between evaporator inlet (T16) and condenser outlet. Due to unlimited seawater access, in the operation recorded on the day shown in Fig. 11 there, was no recirculation of the brine. Thus, 
the condenser inlet temperature (T20) remains constant at seawater temperature around $23^{\circ} \mathrm{C}$ all day. Evaporator outlet temperature $(T 19)$ is recorded at approximately $28^{\circ} \mathrm{C}$.

Further on during the day at 17:39 o'clock, the plant goes into storage operational mode. As the heat in the storage is depleted, the evaporator inlet and condenser outlet temperatures slowly drop and with them, the respective distillate output. Distillate is produced until 0:10 o'clock.

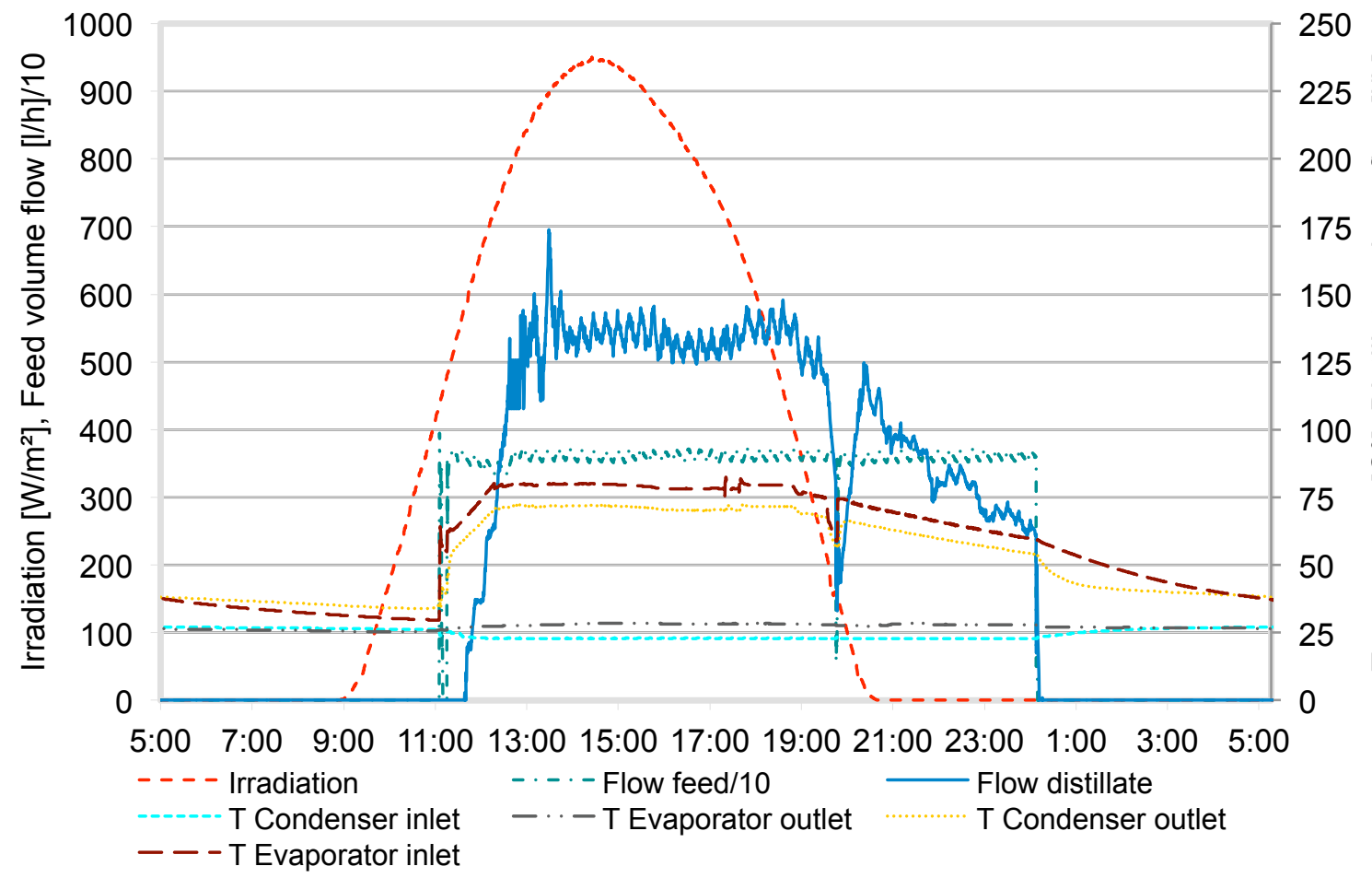

Fig. 11: Data for a sunny day of October 2011, Gran Canary

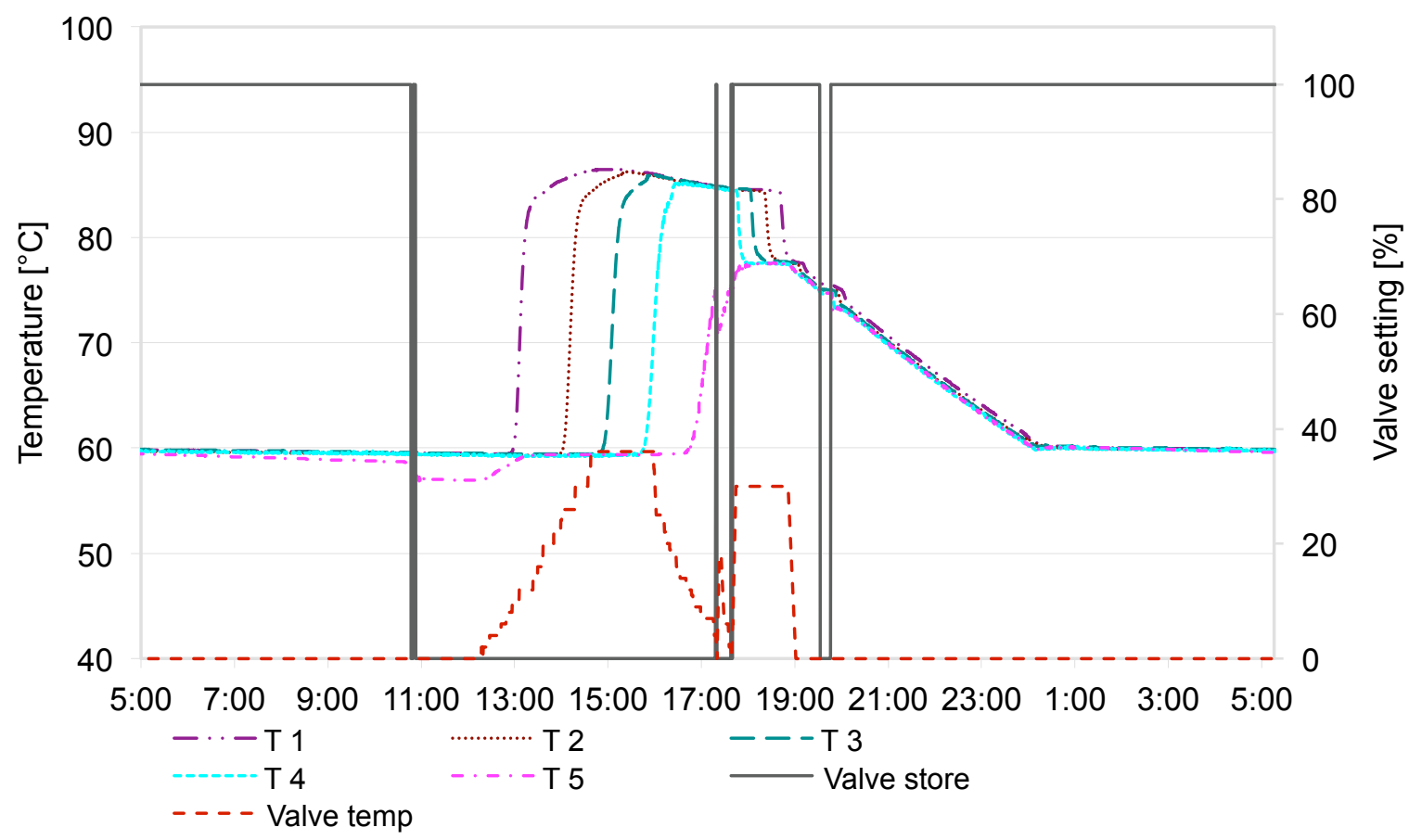

Fig. 12: Charge and discharge of heat storage, Gran Canary 
The heat storage in Gran Canary has five temperature sensors aligned in regular intervals, decreasing in height from T1-T5. In addition, both valve store and valve temp are automatic motor valves controlled by the systems programming sequence. Valve store guides $100 \%$ of the heat from the collectors to the desalination unit, when in this setting (valve setting B-C see Fig.5) and takes all heat from the storage tank, when set to $0 \%$ (valve setting B-A see Fig. 5). In Fig. 12, the valve temp signal is depicted in red color. The increasing opening signal of the valve (valve setting change from B-C to A-C see Fig. 5) can be seen as increasing amount of heat from the collectors is guided into the heat storage, using the cooler tank volume from the bottom to regulate the evaporator inlet temperature (T16). The layering during heating and the discharge in layers can be perceived clearly in Fig. 12. As shown in Fig. 10, the storage is not completely loaded as indicated by a $\mathrm{T} 5$ remaining around $75^{\circ} \mathrm{C}$. The mixing of the volume in the tank takes place faster than in Fig.10, but from a higher temperature level. The repeated activity of valve temp during the discharge is visible between 17:45 - 19:00 o'clock, as it mixes the necessary $80^{\circ} \mathrm{C}$ and switches back to $0 \%$ when the overall temperature level in the tank has dropped under this point.

Once the temperature level in the storage has reached $60^{\circ} \mathrm{C}$ - which is the same temperature as before the loading of the storage - the plant shuts down for efficiency reasons. During the day considered here, 1416 liters were produced at an average of $78 \mu \mathrm{S} / \mathrm{cm}$ out of $1232 \mathrm{kWh}$ solar irradiation.

\section{Energy Balance}

In order to visualize the main daily heat flows and losses throughout the system, the following three diagrams show energy balances for the same three days displayed in Fig. 7 and 9-12.

The heat values are calculated in total amounts per day with the equation:

$$
Q=\int_{\text {start }}^{\text {stop }} \dot{m}(T) * c_{p} * \Delta T(T) * d T
$$

All three plants are equipped with PT 100 temperature sensors, pressure sensors and flow meters, connected to a data logging and control system. Before being inserted into the above equation, temperatures and volume flows from the data acquisition system were cumulated into daily mean values. Calculations where carried out according to (Hoemig, 1978), due to the influence of temperature and salinities on $c_{p}$. Recorded volume flows from the plants were converted to mass flows directly, accepting a density of close to 1 . The base temperature to which the energy values in figures 13, 15 and 16 refer is the condenser inlet temperature of the respective plant. Daytime ambient temperatures hardly vary between the plants on the days selected for the energy analysis and are therefore not taken into consideration. However, they can have an influence on the heat losses and the collector efficiency which must be considered as a possible source of error when evaluating energy data.

The three Sankey-diagrams are arranged in the order followed previously in this work with the presentation of the plants. Fig. 13 depicts the heat flows and losses in Pantelleria, Fig. 15 represents Namibia and Fig. 16 Gran Canary. 


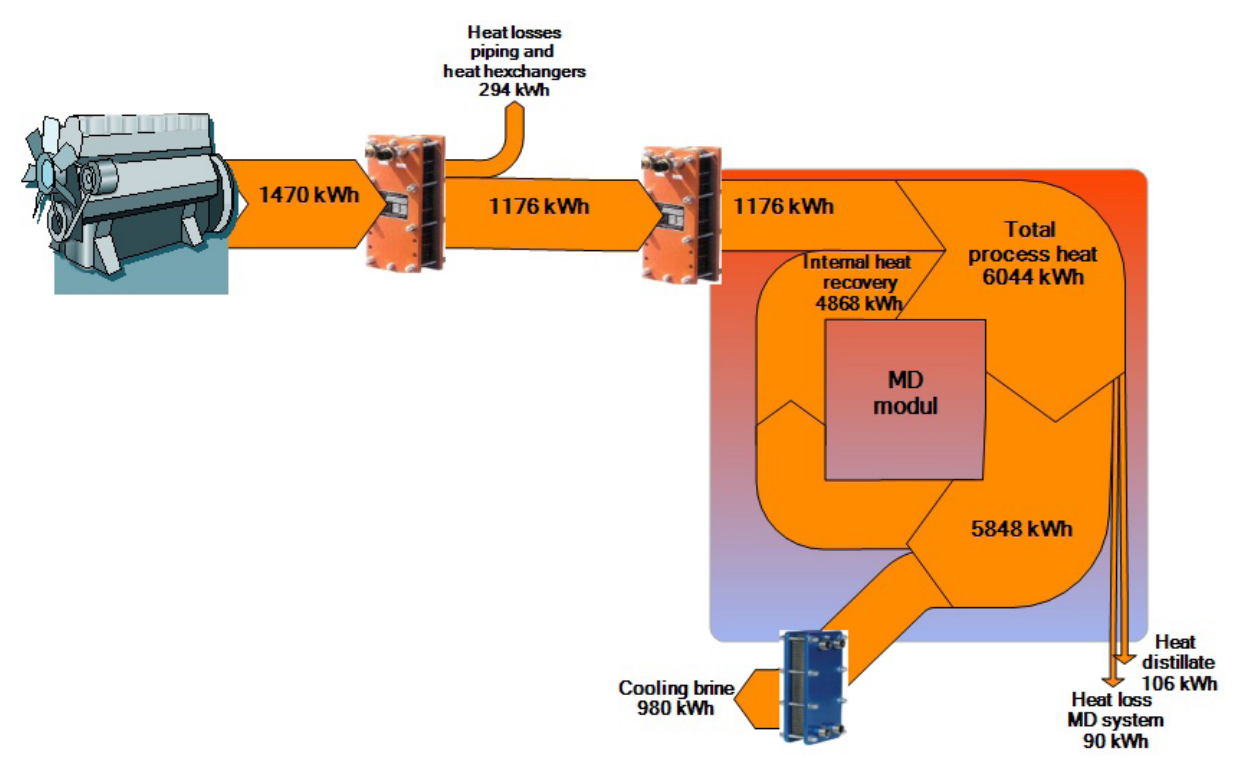

Fig. 13: Heat flows and losses in Pantelleria

Following the diagrams in Fig.s 15 and 16, the first portion of heat deducted from the total does not enter the system as it represents the irradiation before the plant initiates operation. This amount was $53 \mathrm{kWh}$ in Gran Canary and $182 \mathrm{kWh}$ in Namibia. The collector array in Namibia turned faulty shortly after the installation and therefore takes longer to reach operating temperature. The first heat loss is closely linked to collector loop-efficiency. Whereas in Gran Canary the surface areas of the two collector arrays A (single glazed) and B (double glazed) are the same size allowing equal amounts of irradiation to enter, the efficiencies vary due to the different glazing of the collectors. Collector loop A has losses of $378 \mathrm{kWh}$, collector field B only has $359 \mathrm{kWh}$ of $616 \mathrm{kWh}$ entering, describing an integral loop- efficiency of approximately $38 \%$ for collector array A and around $41 \%$ for B. This shows the slightly beneficial effect of double glazing. Another factor on Gran Canary, are the frequently high wind velocities which cause the collector efficiency to sink significantly under the stated efficiency on windy occasions. Fig. 14 shows the difference in temperature under medium and high wind velocities. The data was recorded between 11.00- and 15.00 o'clock on two days with identical ambient temperatures and describes the mean temperature development between collector intake and outlet in correlation with the rising irradiation. The graph gives a good impression of the lower collector temperature on the windier day, not only heating later, but also failing to reach the same temperature level of $95^{\circ} \mathrm{C}$ by around $5 \mathrm{~K}$. On the day with $7.5 \mathrm{~m} / \mathrm{s}$ wind velocity, only $30 \%$ of the heat from irradiation reached the heat circuit through collector array $\mathrm{B}$ and $28 \%$ through collector array A, caused by the wind's cooling effect. Convection is one of the three main thermal losses influencing the efficiency of solar thermal collectors, alongside thermal radiation and reflection. Higher wind velocities enhance convective losses and therefore lower performance. Double glazing provides a better insulation against thermal losses, however transmission is lowered which comes into effect at lower operation temperatures respectively lower ambient to absorber temperature differences. The better insulation of the collectors overweighs at operation temperatures present on site. Not only the double glazing dampens the effect of wind on the collectors of field B slightly, the location is also favorable as collector array A lies more exposed to wind coming from the North and North/East while array B is protected by the project building and desalination unit container on sight. In addition, the experimental setup for bi-phasic operation failed to function leaving a modified hydraulic loop which can not be operated under pressure, a further efficiency dampening factor. 


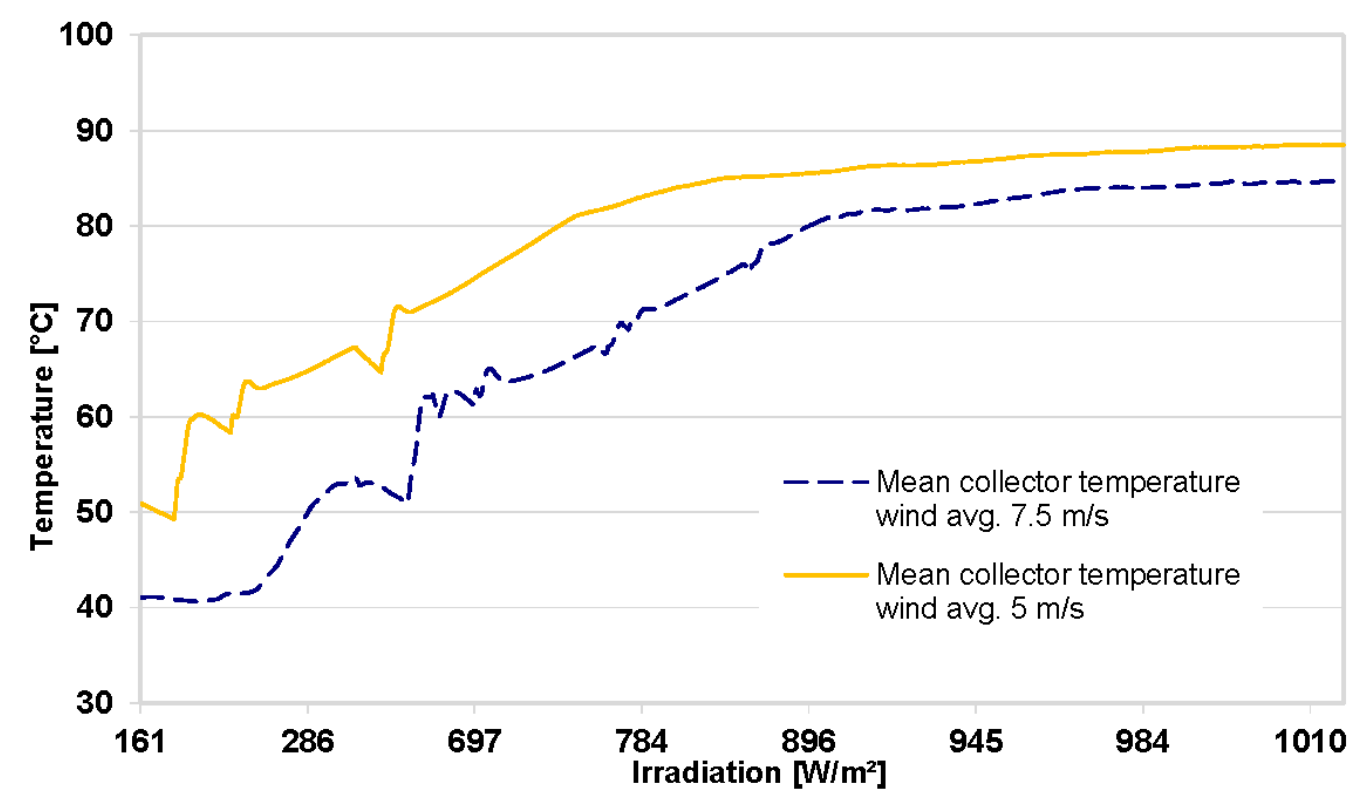

Fig. 14: Difference in mean collector temperature under medium and high avg. wind velocities

In Namibia (Fig.15), 29\% of the heat supplied by irradiation reaches the heat circuit of the MD plant. As mentioned earlier, the collectors were defective resulting in a lower than normal overall performance of the array.

Continuing through the system, a portion of heat is lost at each of the heat exchangers transferring the heat from the collector fields, heat source respectively to the heat circuit. These losses are between $222 \mathrm{kWh}$ in Gran Canary and $294 \mathrm{kWh}$ in Pantelleria. The high loss in Pantelleria can be explained by the long distances between the Diesel generator's cooling circuit and poor insulation of the heat exchangers. In addition, the run time per day is much longer than with the other two plants. In Gran Canary and Namibia piping and heat exchanger losses are similar with $22 \mathrm{kWh}$ and $26 \mathrm{kWh}$. The insulation is very thorough in both cases. In Namibia the storage is located directly inside the system container limiting distances for piping and therefore potential heat losses. In Gran Canary the piping, heat exchangers and storage are set in a cellar, which protects the system components from convective heat losses and the strong winds on sight. 


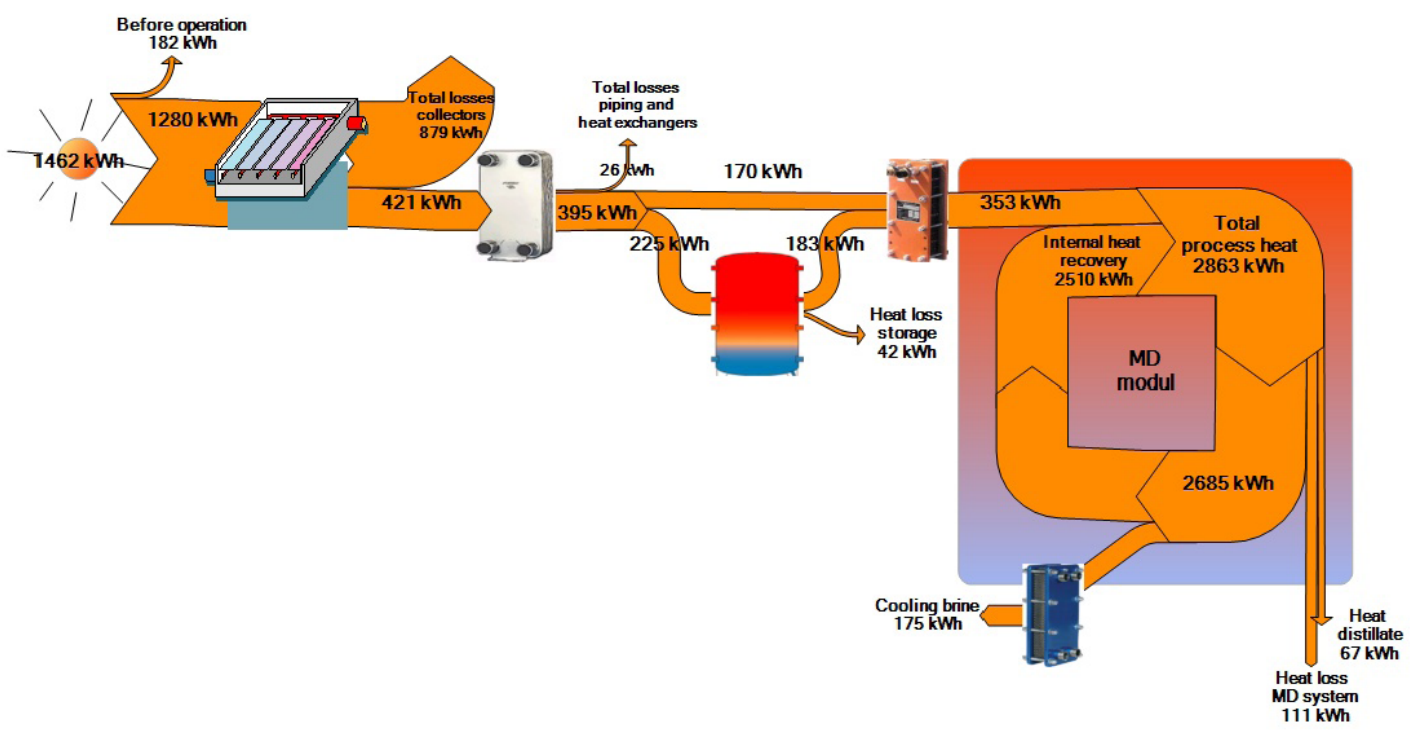

Fig. 15: Heat flows and losses on a sunny day in Namibia

Once entering the heat circuit, the flow is divided into a direct flow to the desalination unit and given a surplus of heat- a flow into the storage tank by the control valves.

The heat storage looses some of this heat internally due to capacity effects and some to the surrounding ambient. These losses also depend on the time required to discharge the storage. 201 $\mathrm{kWh}$ in Gran Canary and $225 \mathrm{kWh}$ in Namibia enter the storage tank, loosing $42 \mathrm{kWh}$ and $58 \mathrm{kWh}$ respectively. .

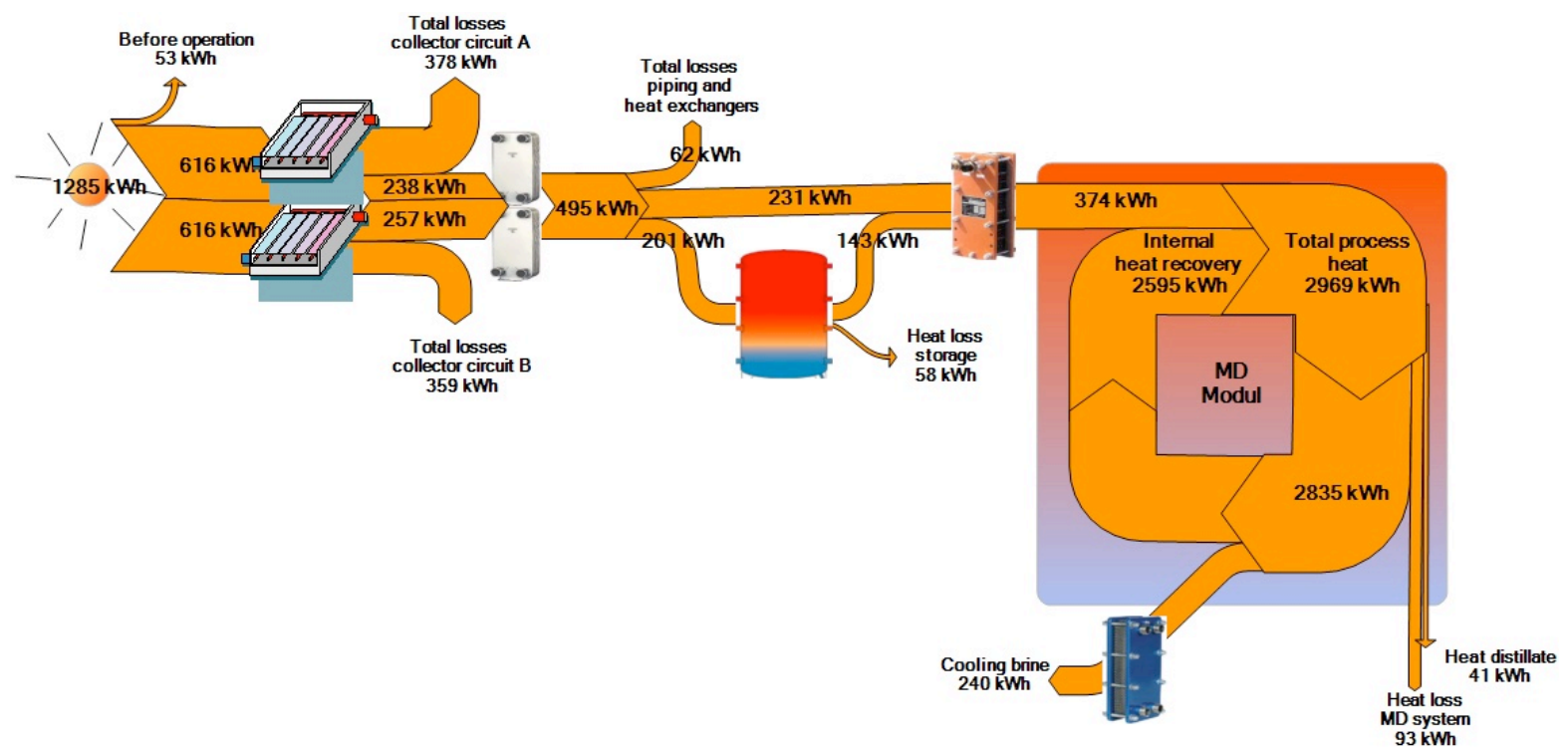

Fig. 16: Heat flows and losses on a sunny day in Gran Canary

After reaching the desalination unit, heat losses are caused by the heat exchanger connecting the heat circuit and the desalination loop. In Pantelleria these losses are summarized in the overall values for Heat losses piping and heat exchangers. Within the desalination unit, the modules give off a certain amount of heat to the surrounding ambient. In Pantelleria $90 \mathrm{kWh}$, in Gran Canary $93 \mathrm{kWh}$ and in Namibia $111 \mathrm{kWh}$ leave the system. This heat loss also contains other small losses inside the desalination units which could not be grasped elsewhere. 
The amount of heat per day required to cool the brine coming from the evaporator outlet before reentering the condenser inlet of the desalination circuit is indicated as Cooling brine. This value is calculated according to Eq. 1 using the temperature difference between the evaporator outlet and condenser inlet temperature and the feed volume flow. It indicates the amount of energy necessary to cool $100 \%$ of the brine back down to the respective condenser inlet temperature which is also the base reference temperature for each energy balance.

A longer time of operation in Pantelleria results in more brine to cool, however the higher evaporator outlet temperature and comparatively low condenser inlet temperature give a higher loss also at this site calculated by eq. (1) and thus $67 \%$ leave the system in Pantelleria compared to $14 \%$ in Gran Canary and $20 \%$ in Namibia.

Heat distillate indicates the heat contained in the distillate leaving the desalination unit as it is warmer than the feed volume flow entering the system. $106 \mathrm{kWh}$ are transported out with the distillate in Pantelleria opposed to $67 \mathrm{kWh}$ in Namibia and $41 \mathrm{kWh}$ in Gran Canary. These values coincide with the runtime and distillate output of the plants.

The three outgoing flows in the desalination unit amount to the total of heat being brought into the system by the collectors.

Tab.3 gives an overview of the main energy flows beginning with the irradiation and assigns percentage values.

\begin{tabular}{lccccccc} 
& Date & $\begin{array}{c}\text { Irradiation } \\
{[\mathrm{kWh}]}\end{array}$ & $\begin{array}{c}\text { Heat circuit } \\
{[\mathrm{kWh}]}\end{array}$ & $\begin{array}{c}\text { Desalination } \\
\text { unit } \\
{[\mathrm{kWh}]}\end{array}$ & $\begin{array}{c}\text { Cooling } \\
\text { brine } \\
{[\mathrm{kWh}]}\end{array}$ & $\begin{array}{c}\text { Loss MD } \\
\text { system } \\
{[\mathrm{kWh}]}\end{array}$ & $\begin{array}{c}\text { Heat } \\
\text { distillate } \\
{[\mathrm{kWh}]}\end{array}$ \\
\hline Pantelleria & 13.11 .2010 & - & 1470 & 1176 & 980 & 90 & 106 \\
\hline & & - & $100 \%$ & $80 \%$ & $67 \%$ & $6 \%$ & $7 \%$ \\
\hline Namibia & 13.05 .2011 & 1279 & 400 & 353 & 175 & 111 & 67 \\
\hline Gran Canary & 11.10 .2011 & $100 \%$ & $32 \%$ & $28 \%$ & $14 \%$ & $9 \%$ & $5 \%$ \\
\hline & & 1232 & 441 & 374 & 240 & 93 & 41 \\
\hline
\end{tabular}

Tab. 3: Summary of outgoings in percentage for the desalination units

MD process efficiency is strongly influenced by the internal heat recovery of the modules. In 24 hours on Pantelleria $4868 \mathrm{kWh}$ are recovered internally, compared to $2510 \mathrm{kWh}$ in 15.3 hours in Namibia and $2630 \mathrm{kWh}$ in 13.16 hours on Gran Canary.

This means a recovery per hour of $202 \mathrm{kWh} / \mathrm{h}$ in Pantelleria, $164 \mathrm{kWh} / \mathrm{h}$ in Namibia and $199 \mathrm{kWh} / \mathrm{h}$ in Gran Canary. These values are however not specific and stand in correlation with the different feed volume flows listed in Tab.5 and under the influence of different salinities listed in Tab.4.

The last value introduced in the Sankey-diagrams is the Total process heat describing the total amount of heat necessary to drive the desalination process. It takes into account the temperature difference between condenser inlet and evaporator inlet (e.g. Fig. 5: T16, T20). For all three plants the internal heat recovery covers $81-88 \%$ of the total process heat.

The values for Namibia and Gran Canary are relatively similar in many respects. In Gran Canary $36 \%$ opposed to the $32 \%$ in Namibia that reach the Heat circuit can be assigned to the higher efficiency of the collector array B on Gran Canary. The higher amount of Cooling brine is connected to the lower condenser inlet and higher evaporator outlet temperature in Gran Canary. Losses from the MD system to the ambient are similar with $8 \%$ and $9 \%$ and the heat leaving the system with the distillate volume flow stands in relation to the produced amounts. 
The values in Pantelleria can not be directly compared to the other two sites, however the $80 \%$ of the initial heat supply reaching the Desalination unit gives a good impression of the good efficiency of waste heat utilization. 67\% Cooling brine represents the difference between condenser inlet and evaporator outlet and is a high percentage of the total due to the relatively low condenser inlet temperature given in the raw sea water around the island of Pantelleria.

\section{Comparison and discussion}

For a comparison of the internal heat recovery in the three plants GOR (gained output ratio) values are calculated by equation

$$
G O R=\frac{\dot{m} d * \Delta h_{v}}{\dot{m} f * c p *\left(T_{\text {evin }}-T_{\text {conout }}\right)}
$$

$\Delta h_{v}$ represents the specific evaporation enthalpy in $\mathrm{kJ} / \mathrm{kg}$ and is multiplied with the amount of distillate produced in order to determine the energy used for the corresponding output. $\Delta h_{v}$ is calculated for the mean temperature between condenser outlet and evaporator inlet.

The energy use is put into relation with the energy actually put into the system externally to create the driving force temperature difference between condenser outlet and evaporator inlet on the feed side of the module. The rest of the energy required is recovered internally.

Specific thermal heat consumption can be described by

$$
q \operatorname{spec}=\frac{\dot{m f} * c p *\left(T_{\text {evin }}-T_{\text {conout }}\right)}{\dot{m d}}
$$

Showing the amount of thermal energy needed for a certain mass flow of distillate. Tab.4 shows a summary of specific thermal energy data with GOR values and different feed water salinities.

\begin{tabular}{lccccccc} 
& Date & $\begin{array}{c}\text { Feed salinity } \\
{[\mathrm{g} / \mathrm{kg}]}\end{array}$ & $\begin{array}{c}\text { Distillate } \\
{\left[\mathrm{m}^{3} / \mathrm{d}\right]}\end{array}$ & $\begin{array}{c}\text { qspec real } \\
{\left[\mathrm{kWh} / \mathrm{m}^{3}\right]}\end{array}$ & $\begin{array}{c}\text { qspec stat } \\
{\left[\mathrm{kWh} / \mathrm{m}^{3}\right]}\end{array}$ & $\begin{array}{c}\text { qspec lab } \\
{\left[\mathrm{kWh} / \mathrm{m}^{3}\right]}\end{array}$ & $\begin{array}{c}\text { GOR stat } \\
{[-]}\end{array}$ \\
\hline Pantelleria & 13.11 .2010 & 49 & 3.69 & 300 & 300 & 285 & 2.4 \\
\hline Namibia & 13.05 .2011 & 25 & 2.08 & 171 & 160 & 150 & 4.4 \\
\hline Gran Canary & 11.10 .2011 & 35 & 1.4 & 271 & 236 & 192 & 3.1 \\
\hline
\end{tabular}

Tab.4: Summary of specific thermal energy consumptions and GOR values

In comparison to the qspec lab values the qspec stat values show a satisfactory operation of all three plants. The differences are low to medium with 5-23\% discrepancies.

Qspec real indicates the heat used to produce the listed amount of distillate. The heat entering the desalination unit, visible in Tab. 3, divided by the distillate per day calculates this value. However, when observing the specific heat consumption per day it must be taken into consideration that morning and evening run up and run down phases have a significant influence on this value and these phases can differ from day to day. It is more objective to compare the specific heat consumption values for near stationary operation conditions during the day, namely qspec stat. Qspec lab gives a value measured in the Fraunhofer ISE laboratory facilities under optimal conditions on single MD modules. The laboratory setup used for the measurements on which qspec lab are based is described by (Winter, 2011). GOR stat values are calculated with the same heat used 
in qspec stat. The numerator contains the amount of distillate listed in Tab. 4 multiplied with a $\Delta h_{v}$ of $2502 \mathrm{~kJ} / \mathrm{kg}$.

Different parameters lead to the discrepancies between the qspec field and lab values and the plants among one another. Firstly, the higher the salinity of the feed water, the more energy is needed to distill due to a lowering in driving force vapor pressure difference, the effect being discussed in (Winter, 2011) together with the effect of feed volume flow and other significant influencial parameters. However, the overall lower energy consumption of the Namibia system can additionally be linked to the extended module channel length, raising the internal heat recovery and therefore the efficiency of the modules. The highest GOR value of 4.4 confirms this effect as it reflects the internal heat recovery of the desalination unit.

Even though operated at primary design temperature of $80^{\circ} \mathrm{C}$, Gran Canary plant does not reach the qspec lab value of $192 \mathrm{kWh} / \mathrm{m}^{3}$, due to the further efficiency dampening effect of unevenly distributed feed water among the modules and between condenser and evaporator channels. In addition, with Gran Canary the condenser inlet temperature is $22.8^{\circ} \mathrm{C}$ as opposed to the design temperature of $25{ }^{\circ} \mathrm{C}$ which adds to the specific energy demand. The influence of condenser inlet temperature and salinity on the MD process is investigated and discussed in (Winter, 2011).

In Pantelleria relatively high specific thermal heat consumption is the result of high feed salinity. Due to the unlimited heat supply by the Diesel power plant, long term testing at high recirculation and high feed salinities is an aim in long term testing. Thus, the small difference to the qspec lab value shows satisfactory operation in this mode.

The alignment of the modules in rows of $3 \times 4$ or $2 \times 6$ has further energy raising effects on the flow distribution which can not be calculated with the installed measuring instrumentation. The arrangement of $2 \times 6$ has proven especially disadvantageous for an even flow distribution between the modules and adds to the specific energy consumption shown in Tab. 4. Gran Canary plant with a 2x6 setup, presents the largest difference between qspec stat and qspec lab.

Empirical research carried out at the Fraunhofer ISE confirmed the correlation between uneven feed flow distribution between condenser and evaporator and an increase in specific heat consumption. A linear equation for the energy consumption containing the mass flow deviation could be identified as qspec $=34,939 *$ feed flow deviance +13982 in Watts. However, test series were only carried out for a salinity of $50 \mathrm{~g} / \mathrm{kg}$ an evaporator inlet temperature of $80^{\circ} \mathrm{C}$ and a feed volume flow of $400 \mathrm{~kg} / \mathrm{h}$, and a four MD module setup not allowing a direct comparison in this work, as the volume flow deviations were not recorded for single modules in the plants discussed in this work. Further, investigations on the parallelization of MD modules will be published elsewhere.

Furthermore, the influence of the evaporator inlet temperature on the efficiency of the MD process can be explained by referring to the thermal efficiency described as

$$
\begin{aligned}
& \dot{q}_{s}=\frac{\lambda_{M}}{\delta_{M}} *\left(T_{1}-T_{0}\right) \\
& \dot{q}_{l}=C *\left(p_{1}-p_{0}\right) * \Delta h_{v}=C * \frac{d p}{d T} *\left(T_{1}-T_{0}\right) * \Delta h_{v} \\
& \eta_{t h}=\frac{\dot{q}_{l}}{\dot{q}_{t}}=\frac{\dot{q}_{l}}{\dot{q}_{l}+\dot{q}_{s}}
\end{aligned}
$$


$\dot{q}_{l}$ and $\dot{q}_{s}$ represent the latent heat transfer and sensible heat conduction through the membrane and are introduced by (Winter, 2011). Latent heat is directly linked to the distillate production, whereas sensible heat leads to a reduction of the driving force. Thereupon, the relation of latent heat transfer to the complete heat transfer describes the thermal efficiency. Due to the increasing slope of the vapor pressure curve, the driving forces rise with rising evaporator inlet and mean process temperature. The portion of sensible heat even drops with the increase in temperature. This correlation is further discussed with (Koschikowski, 2010). Resent investigations have also highlighted the influence of $\Delta \mathrm{T}$ and $\Delta \mathrm{P}$ driving force in systems with different channel configurations (including AGMD and PGMD as in the present case) also indicating a similar behaviour of the system (Cipollina, 2012; Porrazzo et al., 2013)

\begin{tabular}{lccccccc} 
& Date & $\begin{array}{c}\text { Tcondin } \\
{\left[{ }^{\circ} \mathrm{C}\right]}\end{array}$ & $\begin{array}{c}\text { Tevin } \\
{\left[{ }^{\circ} \mathrm{C}\right]}\end{array}$ & $\begin{array}{c}\Delta T_{h} \\
{[\mathrm{~K}]}\end{array}$ & $\begin{array}{c}\text { MD channel } \\
\text { length } \\
{\left[\mathrm{m} ; \mathrm{m}^{2}\right]}\end{array}$ & $\begin{array}{c}\text { Feed volume } \\
\text { flow } \\
{[1 / \mathrm{h} / \mathrm{md}]}\end{array}$ & $\begin{array}{c}\text { GOR stat } \\
{[-]}\end{array}$ \\
\hline Pantelleria & 13.11 .2010 & 22 & 72 & 9.4 & $7 ; 10$ & 387 & 2.4 \\
\hline Namibia & 13.05 .2011 & 30 & 70 & 4.9 & $10 ; 14$ & 356 & 4.4 \\
\hline Gran Canary & 11.10 .2011 & 23 & 80 & 8 & $7 ; 10$ & 302 & 3.1 \\
\hline
\end{tabular}

Tab. 5: Summary of operational conditions with GOR stat values

Tab. 5 gives a summary of the operational conditions on the three days analysed in this work.

Pantelleria has a the highest energy demand of the three, linked to the high salinity of $49 \mathrm{~g} / \mathrm{kg}$, the highest feed volume flow and a low Tcondin.

The longer $14 \mathrm{~m}^{2}$ modules in Namibia present a higher heat recovery and efficiency than the $10 \mathrm{~m}^{2}$, combined with the lowest feed salinity and a high Tcondin. This results in the highest GOR value. Although Gran Canary is operated at $80^{\circ} \mathrm{C}$ Tevin, the low Tcondin and uneven flow distribution lead to a GOR of 3.1 at a salinity of $35 \mathrm{~g} / \mathrm{kg}$. The condenser inlet temperatures are predetermined by the raw water conditions on the different sites and can be influenced by recirculating the brine from the evaporator outlet leading to an increase of feed water salinity. This work is based on data without brine recirculation in order to allow a better comparison of plant operation. For regions with scarce water resources brine recirulation and high recovery rates can be decisive for the choice of a suitable technology. Here, the effects of higher feed water salinities and therefore higher specific energy demands must be taken into consideration.

A final analysis is given on the influence of daily irradiation (in $\mathrm{Wh} / \mathrm{m}^{2}$ ) on the distillate output of the plants in Namibia and Gran Canary in Fig. 17. 


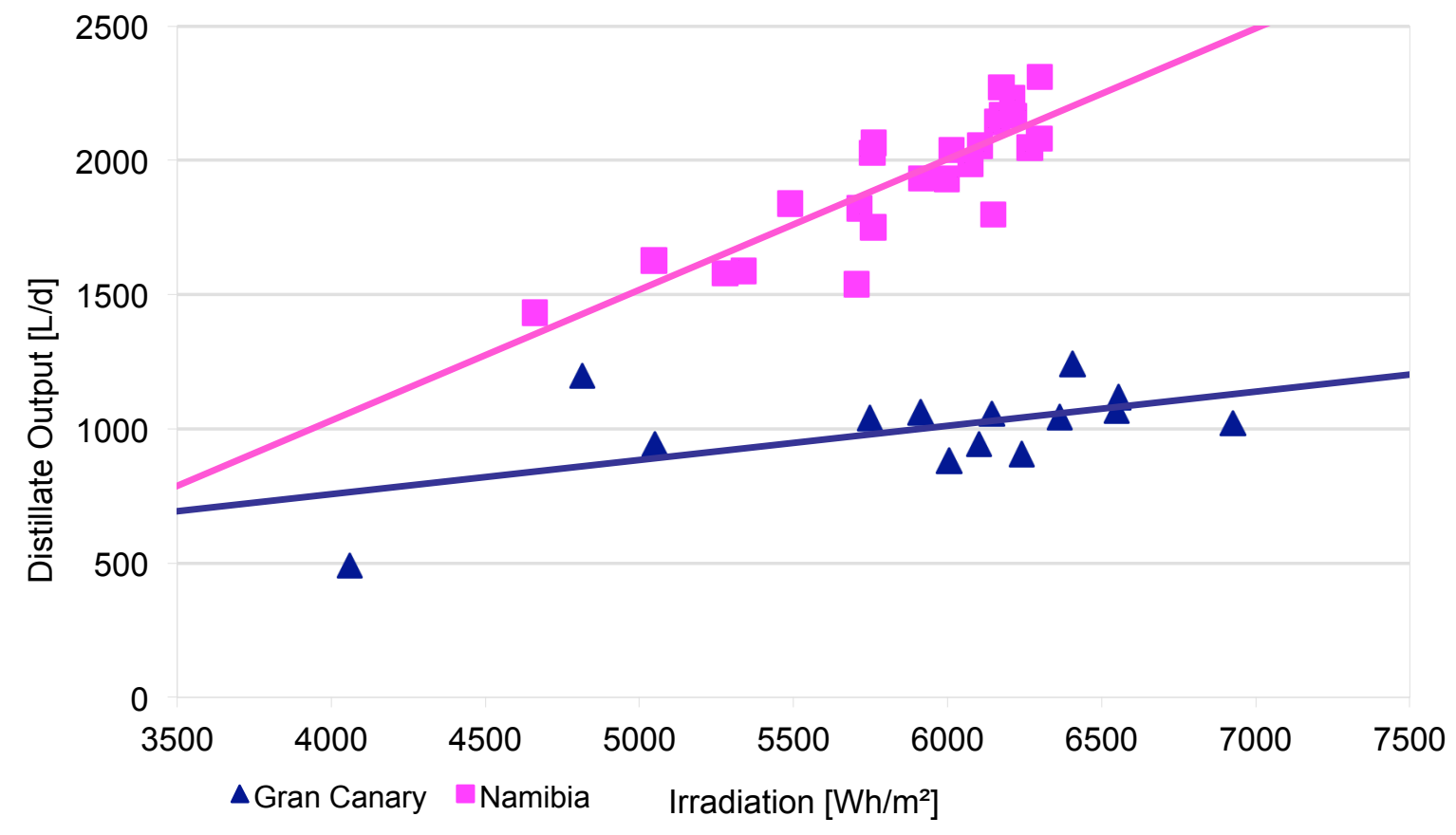

Fig. 17: Impact of daily solar irradiation on distillate output

The correlation of irradiation and distillate output grasps all factors and losses between the primary energy source and the product outcome.

Visible differences between the output per $\mathrm{Wh} / \mathrm{m}^{2}$ in Namibia and Gran Canary can be assigned to several main influencial factors. The difference in qspec real given in Tab. 4 due to the lower salinity and longer MD module channel length in Namibia account for a large portion of the deviation between the two sites' distillate outputs. Wind conditions influencing the collector efficiency explained in sec. 4 also have an impact on the amount of output per $\mathrm{Wh} / \mathrm{m}^{2}$.

\section{Conclusions}

Three membrane distillation plants were developed by the Fraunhofer ISE in the years 2010 and 2011. All three plants had a different approach basically with respect to energy supply, hydraulic lay out or MD module configuration. They were successfully operated and monitored in different testing periods under a variety of conditions. From the collected data, analyses were carried out concerning the energy efficiency and distillate output of the plants. On this basis comparisons could be made between solar powered and waste heat powered membrane distillation systems. Each plant also has a different setup regarding condenser and evaporator inlet temperatures, feed water salinities and feed volume flow. The longer MD channel length in Namibia proved beneficial regarding specific energy consumption however, the salinity of the raw water is the lowest here, which is favorable for the lower driving force temperature difference which comes with the longer channel length and higher condenser inlet temperature. These modules can be applied, but only if the conditions are suitable. For seawater salinities as in Pantelleria and Gran Canary, standard channel lengths of $7 \mathrm{~m}$ are advantageous giving driving force temperature differences between $8 \mathrm{~K}-9.4 \mathrm{~K}$.

The collected data allowed the presentation of the correlations between driving force temperature difference, specific energy demand and GOR values with the respective influences of salinities and feed volume flows which had previously only been investigated at the Fraunhofer ISE laboratory to such an extent. 
Through the presented energy analysis major heat losses could be identified.

Defective collectors and higher than expected heat losses in the collector array on Gran Canary did not allow an operation to the complete potential of the desalination units. In future projects, factors influencing the collector efficiency must be considered more carefully beforehand. For example, the experimental bi-phasic setup in collector array A on Gran Canary was not successful, leaving an array with less than normal efficiency due to the experimental modifications.

Within the energy analysis of the desalination unit, the high internal heat recovery of the MD process could be shown and compared with respect to different daily operating hours of the plants. Waste heat from combustion engines proves to be a promising energy source, supplying a temperature level suitable for MD. If a constant waste heat source is available it is possible and financially beneficial to save the investment costs of a solar thermal collector array.

When comparing the impact of daily irradiation on the daily distillate output between Namibia and Gran Canary in Fig. 17 the influence of the different main operational parameters salinity, evaporator inlet temperature and MD channel length is visualized clearly.

Room for improvement is indicated as lowering the main heat losses through better insulation and carefully choosing the size of heat storage tanks by analyzing the difference between losses caused by the operation of large tanks and the energy consumption by raising the feed volume flow in order to use the heat directly as an alternative. For the modules and system as a whole, a thorough analysis of the site and raw water conditions and adaptation of channel length and evaporator inlet temperature according to the available heat source, appears to be the most promising way of finding an efficient plant configuration and setup. These measurements present a meaningful basis, for further plant designs in that respect.

Ongoing, long term testing is envisaged for all three sites in order to further investigate the potential of autonomous, solar powered MD plants. The product water can be used for drinking in Namibia and is used for irrigation on Gran Canary, in both cases without post treatment. In Pantelleria the low conductivity distillate is used for an industrial process within the power plant.

\section{References}

Banat, F., Jwaied, N., Rommel, M., Wieghaus, M., \& Koschikowski, J. (2007). Desalination by a "compact SMADES" autonomous solar-powered membrane distillation unit. Desalination 271, 29-37.

Cipollina, A., Micale, G., Rizzuti, L.(2011), A brine evaporative cooler/concentrator for autonomous thermal desalination units, Desalination and Water Treatment 31 (1-3), 2011 , 269-278Cipollina,A., Cipollina, A., Di Sparti M.G., Tamburini A., Micale G. (2012), Development of a Membrane Distillation module for solar energy seawater desalination Chem. Eng. Research and Design, 90, 2101-2121.

Cipollina A., Di Miceli A., Koschikowski J., Micale G., Rizzuti L. (2009) CFD simulation of a membrane distillation module channel, Desalination and Water Treatment, Vol.6, pp.177-183. Hoemig, H. (1978). Seawater and seawter desalination, Fichtner Handbook. Germany: Vulkan Verlag.

Koschikowski, J. (2010). Entwicklung von energieautark arbeitenden Wasserentsalzungsanlagen auf Basis der Membrandestillation.

Koschikowski, J., Wieghaus, M., Rommel, M., Subiela, V., Penate, B., \& Betancort, J. (2009). Experimental investigations on solar driven stand-alone membrane distillation systems for remote areas. Desalination 248, 125-131. 
Porrazzo R., Cipollina A., Galluzzo M., Micale G. (2013) A neural network-based optimizing control system for a seawater-desalination solar-powered membrane distillation unit, Computers \& Chemical Engineering, accepted for publication.

Raluy, G., Schwantes, R., Subiela, V., Penate, B., Melian, G., \& Betancort, J. (2011). Operational experience of a solar membrane distillation demonstration plant in Pozo Izquierdo-Gran Canaria Island (Spain).

Wieghaus, M., Koschikowski, J., \& Rommel, M. (2008). Solar membrane distillation ideal for remote areas. D\&WR 18 (3), 37-40.

Winter, D., Koschikowski, J., \& Wieghaus, M. (2011). Desalination unsing membrane distillation:Experimental studies on full scale spiral wound modules.

\section{Acknowledgements}

We acknowledge the funding of the project Membrane Distillation in Remote Areas by from the European Union in the $7^{\text {th }}$ framework program and the funding of the CUVE waters project by Federal Ministry of Education and Research. We thank the Instituto Tecnologico de Canarias and the Università di Palermo for their extensive support and all other partners within the MEDIRAS project. Thanks also to SMEDE Pantelleria SpA for hosting the pilot system within the power station premises and SO.FI.P SpA for financially supporting some of the research activities carried out on the pilot system in Pantelleria. 